\title{
Chapter 4 \\ Responses of Tropical Bats to Habitat \\ Fragmentation, Logging, and Deforestation
}

\author{
Christoph F.J. Meyer, Matthew J. Struebig and Michael R. Willig
}

\begin{abstract}
Land-use change is a key driver of the global biodiversity crisis and a particularly serious threat to tropical biodiversity. Throughout the tropics, the staggering pace of deforestation, logging, and conversion of forested habitat to other land uses has created highly fragmented landscapes that are increasingly dominated by human-modified habitats and degraded forests. In this chapter, we review the responses of tropical bats to a range of land-use change scenarios, focusing on the effects of habitat fragmentation, logging, and conversion of tropical forest to various forms of agricultural production. Recent landscape-scale studies have considerably advanced our understanding of how tropical bats respond to habitat fragmentation and disturbance at the population, ensemble, and assemblage level. This research emphasizes that responses of bats are often species and ensemble specific, sensitive to spatial scale, and strongly molded by the characteristics of the prevailing landscape matrix. Nonetheless, substantial knowledge gaps exist concerning other types of response by bats. Few studies have assessed responses at the genetic, behavioral, or physiological level, with regard to disease prevalence, or
\end{abstract}

\footnotetext{
C.F.J. Meyer $(\bowtie)$

Centre for Ecology, Evolution, and Environmental Changes, Faculty of Sciences,

University of Lisbon, Lisbon, Portugal

e-mail: cmeyer@fc.ul.pt

M.J. Struebig

Durrell Institute of Conservation and Ecology, School of Anthropology and Conservation, University of Kent, Canterbury, UK

e-mail: m.j.struebig@kent.ac.uk

M.R. Willig

Center for Environmental Sciences and Engineering and Department of Ecology and Evolutionary Biology, University of Connecticut, Storrs, CT, USA

e-mail: michael.willig@uconn.edu
} 
the extent to which human disturbance erodes the capacity of tropical bats to provide key ecosystem services. A strong geographic bias, with Asia and, most notably, Africa, being strongly understudied, precludes a comprehensive understanding of the effects of fragmentation and disturbance on tropical bats. We strongly encourage increased research in the Paleotropics and emphasize the need for long-term studies, approaches designed to integrate multiple scales, and answering questions that are key to conserving tropical bats in an era of environmental change and dominance of modified habitats (i.e., the Anthropocene).

\subsection{Habitat Conversion: A Key Aspect of Global Change}

Bats are valuable indicators of biodiversity and ecosystem health, and respond to a range of stressors related to environmental change (Jones et al. 2009). Alteration in land use is one of the principal aspects of global environmental change and a key driver of biodiversity loss in terrestrial ecosystems. Indeed, biodiversity impacts of land-use change are generally considered to be more immediate than those from climate change (Sala et al. 2000; Jetz et al. 2007; Pereira et al. 2010). However, the effects of land-use change on tropical species could exacerbate those of changing climate, leading to challenges for long-term conservation efforts (Struebig et al. 2015), including those for bats. Over the last decades, human transformation of much of the Earth's natural ecosystems has greatly accelerated, and the twenty-first century will herald profound changes in land use, particularly in developing tropical countries (Lee and Jetz 2008). The most recent quantification of global forest change revealed an overall increasing trend in annual forest loss across the tropics between 2000 and 2012 (Hansen et al. 2013), highlighting the continued prevalence of tropical deforestation.

Drivers of tropical deforestation have shifted from being promoted mostly by government policies for rural development toward urban population growth and industrial-scale, export-oriented agricultural production (DeFries et al. 2010). Fueled by unabated human population growth, global food demand is escalating, and the current trajectory of agricultural expansion will have serious negative long-term consequences for the preservation of the planet's biodiversity (Tilman et al. 2011; Laurance et al. 2014). In tropical countries, conversion of natural habitats to agricultural and pastoral land is one of the greatest threats to biodiversity (Phalan et al. 2013), as cropland expansion in recent decades has largely come at the expense of intact old-growth forest (Gibbs et al. 2010). Rampant commercial logging is also a major force of tropical forest destruction and degradation, with around $20 \%$ of such forests subjected to some level of timber harvesting (Asner et al. 2009).

Loss of habitat as a result of extensive land conversion and associated fragmentation are ubiquitous throughout the tropics. Resulting landscapes typically comprise a mosaic of human-modified habitats that include agroforests, agricultural land, and tree plantations, as well as remnants of old-growth, logged forest, and secondary forests regenerating from clearance or burning (Gardner et al. 2009; Chazdon 2014). 
Indeed, except for large areas of tropical forest in Papua New Guinea and in the Amazon and Congo basins, such a description accurately characterizes most tropical landscapes (Melo et al. 2013). Anthropogenic activities in many tropical countries have resulted in the creation of fragmented landscapes that are dominated by small (often $<50$ ha), isolated, and irregularly shaped forest patches. These patches are highly prone to edge effects (Broadbent et al. 2008; Ribeiro et al. 2009), defined as systematic changes in abiotic and biotic variables at the boundary between adjacent land-use types. Although deforestation and degradation of old-growth forests are the dominant forms of land-use alteration, forest regeneration and the expansion of secondary forests are the second most important type of land-use change occurring across the tropics (Asner et al. 2009; Dent and Wright 2009). These recovering forest habitats could potentially mitigate, or even reverse, current trends of forest loss and degradation as well as concomitant biodiversity loss (Wright and MullerLandau 2006; Dent and Wright 2009; Chazdon 2014). A pan-tropical meta-analysis of land-use change studies points to the irreplaceable value of old-growth forests, but also highlights the high species diversity found in regenerating logged forests compared to secondary forests (Gibson et al. 2011). Although the long-term conservation value of regenerating forests has been questioned (Melo et al. 2013), biodiversity representation clearly varies among logged and secondary habitats, and so not all recovering forests should be treated equally.

\subsection{Tropical Bats in a Changing World}

Bats exhibit the general mammalian pattern of greatest diversity in the tropics, from both a taxonomic and a functional perspective (Willig et al. 2003). Bats also provide ecosystem services that are critically important in tropical ecosystems - as pollinators and seed dispersers for hundreds of plant species and as agents of suppression of arthropod herbivores and insect pest species (Muscarella and Fleming 2007; Kalka et al. 2008; Williams-Guillén et al. 2008; Kunz et al. 2011; Maas et al. 2013). Nonetheless, many tropical bat species face an uncertain future and show declining population trends due to many of the threats outlined previously (e.g., Kingston 2013).

How do tropical bats fare in the Anthropocene, in which they are exposed to increasing levels of land-use change, potentially exacerbated by climate change (Struebig et al. 2015), and the synergistic effects of both processes? Simple pantropical meta-analyses suggest that the impacts of land-use change on mammal diversity, particularly on bats, are somewhat less severe than for other animal groups (Gibson et al. 2011). Nevertheless, such studies can potentially miss subtle, yet important, responses in assemblage structure. In this chapter, we summarize the accumulated knowledge on the responses of tropical bats to human-induced habitat fragmentation and forest disturbance. By providing a synthetic overview of the topic, we hope to shed light on the conservation value of anthropogenically modified habitats for bats across the major tropical regions and identify future research priorities. 


\subsection{Review Methodology}

We followed a systematic review methodology (Pullin and Stewart 2006) to synthesize information about tropical bat responses to habitat fragmentation, logging, and deforestation. Studies were identified through a comprehensive search in the ISI Web of Science online database (accessed in September 2013), performing a topic search using the string "bat? AND *tropic* AND (fragment* OR logg* OR deforest* OR disturb*)," without restriction on publication year. The use of this combination of key words allowed for the identification of an inclusive set of studies on the effects of fragmentation, logging, and disturbance on tropical bats. The search identified 248 publications that were subsequently screened for suitability for the review based on the article's title, abstract, and, when necessary, text. We excluded review articles and studies that were conducted in urban landscapes (see Chap. 2). As our purpose here was to review evidence for the effects of anthropogenic habitat modification on tropical bats, we also excluded studies that were conducted in naturally fragmented landscapes (e.g., forest islands embedded in savannah, oceanic islands). Our review thus focuses on a range of human-modified matrix types of varying structural complexity and contrast-from relatively low-contrast secondary forests, agroforests, and plantation forests, to high-contrast agricultural fields and water matrices resulting from dam construction.

From the 248 studies, 93 met our criteria. In addition, we extended our search using the same key word combinations in Google Scholar through which we identified an additional eight relevant studies within the first 100 records. Sixteen additional publications were found based on a search of our own literature databases, thus bringing the total number of studies considered in our synthesis to 117. Each article was characterized according to geographic region, taxonomic focus, response type, and disturbance type. Response types included (a) population- and assemblage-level responses, (b) genetic effects, (c) behavioral responses, (d) physiological responses, parasite and disease prevalence, and (e) effects on the provisioning of ecosystem services. Disturbance type included the following broad categories: (a) habitat fragmentation, (b) logging, (c) secondary forests and succession, (d) agroforestry systems, (e) tree plantations, and (f) agriculture.

\subsection{Biases in Our Understanding of Responses of Tropical Bats to Habitat Alteration}

The collated literature revealed substantial geographic and taxonomic biases in the current understanding of tropical bat responses to anthropogenic disturbance. Studies covered 34 distinct study landscapes in 21 countries. Despite a general increase in the number of studies over the last 20 years (Fig. 4.1), most research has been undertaken in the New World tropics (96 studies), with research in Southeast Asia and Australasia lagging far behind (19 studies) and studies in 


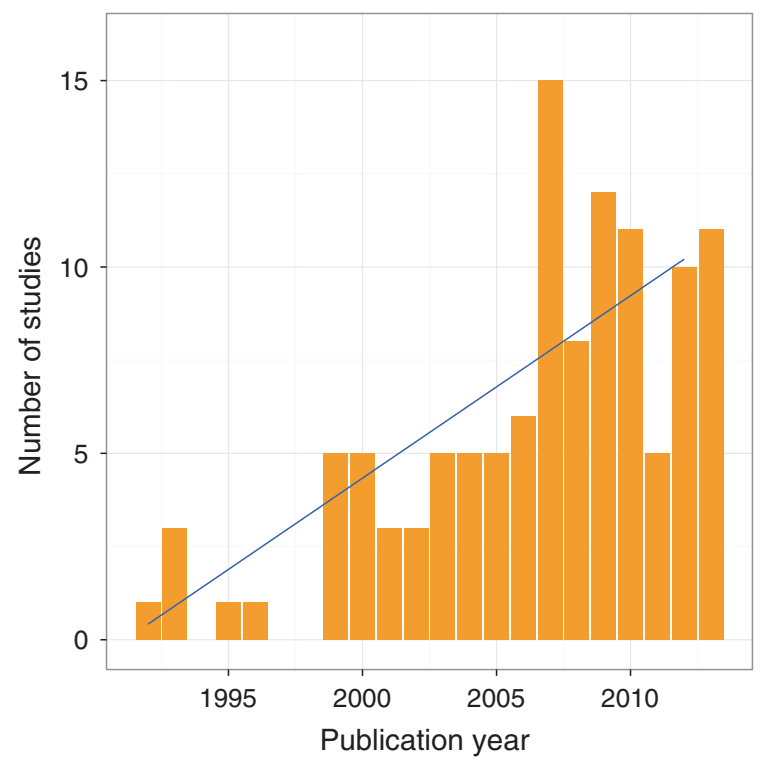

Fig. 4.1 Number of publications on the effects of fragmentation, logging, or disturbance on tropical bats based on a systematic search of the literature. There is a general increase in publications over the last 20 years (linear model fit, $R_{\mathrm{ad}}^{2}=0.55, p<0.001$ ). Data for 2013 represent an underestimate as the literature search did not include the entire year, and therefore, they were not considered in the model fit

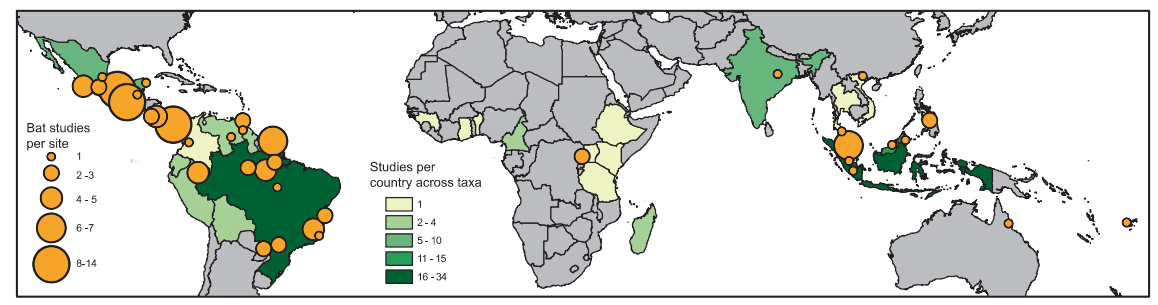

Fig. 4.2 Map illustrating the geographic distribution of research effort based on 117 studies of bats in anthropogenically modified landscapes. Sizes of orange circles represent the number of studies per site, where a site is defined as a particular study landscape. Colors of tropical countries represent the number of studies based on the pan-tropical analysis of the impact of disturbance and land conversion on birds, mammals, arthropods, and plants by Gibson et al. (2011)

Africa being rare (2 studies; Fig. 4.2). Geographic variation in this research effort (Fig. 4.2) broadly parallels the pattern reported for multiple taxa across the tropics (Gibson et al. 2011). A few notable differences include a disproportionately high number of bat studies in Mexico and low number of studies in Indonesia compared to other taxa. A large taxonomic bias therefore characterizes our understanding of disturbance effects on tropical bats as a consequence of the prevalence of studies in the Neotropics. With a few exceptions (Estrada et al. 2004; Estrada Villegas 
(a)

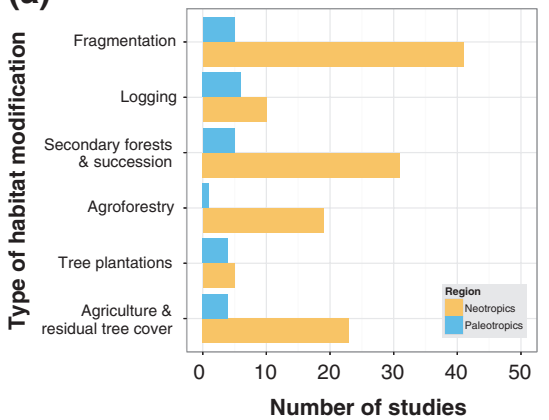

(b)

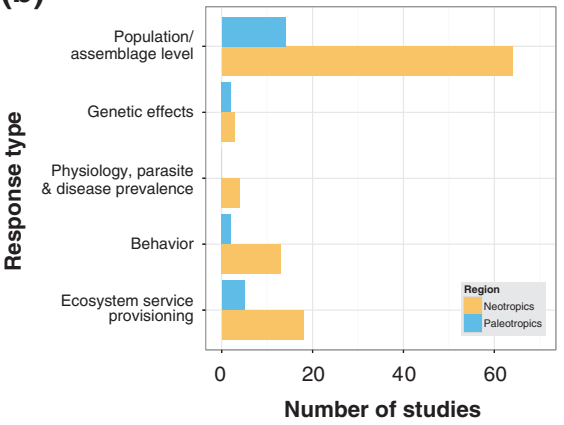

Fig. 4.3 Number of studies by region (Neotropics $[n=96$ studies $]$ vs. Paleotropics $[n=21$ studies]) based on a type of disturbance or habitat modification and $\mathbf{b}$ type of response. Studies in many cases, especially for (a), matched more than one of the broad categories and were counted multiple times

et al. 2010; Williams-Guillén and Perfecto 2011), New World studies focused on the species-rich Phyllostomidae, in turn largely reflecting the use of mist nets to capture bats. Phyllostomids are easily sampled with mist nets and dominate studies. In contrast, non-phyllostomids are underrepresented in samples based on mist netting. Although acoustic methods hold much promise for sampling non-phyllostomid and non-pteropodid bats, considerable difficulties remain in the wider implementation of these techniques in tropical countries, including the lack of call libraries, taxonomic uncertainty, and practical challenges of tropical climates (Harrison et al. 2012). As a result, acoustic sampling has not yet been employed intensively in landscape-scale studies of tropical bats (see also Cunto and Bernard 2012). Finally, a considerable bias exists with respect to studied aspects of fragmentation and disturbance. Comparatively few studies have targeted bat responses to logging or agroforestry (Fig. 4.3a). The vast majority of studies evaluated responses at the population or assemblage level. Far fewer have examined the consequences of anthropogenic disturbance for the provision of ecosystem services by bats. Genetic, physiological, and behavioral effects remain poorly explored, as do effects on disease dynamics associated with bat hosts (Fig. 4.3b).

\subsection{Responses at the Population and Assemblage Level}

\subsubsection{Habitat Fragmentation}

Habitat fragmentation has become a major research theme in conservation biology, as reflected in the burgeoning literature on the subject (Fahrig 2003; Ewers and Didham 2006a; Lindenmayer and Fischer 2006; Fischer and Lindenmayer 2007; Collinge 2009). Although the exact definition of "habitat fragmentation" 
is contentious (Fahrig 2003; Ewers and Didham 2007; Fischer and Lindenmayer 2007), we follow a widely used definition - the landscape-scale process by which habitat loss results in the subdivision of continuous habitat into smaller patches that are isolated from each other by a matrix of modified habitat (Didham 2010).

\subsubsection{General Patterns}

Despite numerous and increasing attempts to detect consistent responses of tropical bats to habitat fragmentation, studies to date suggest relatively few generalizations. At the population level, many studies have documented that abundance responses to fragmentation are highly species and ensemble specific. For instance, in the Neotropics, abundances of gleaning animalivorous bats (Pons and Cosson 2002; Meyer et al. 2008; Meyer and Kalko 2008a) and certain forest-dependent aerial insectivores (Estrada Villegas et al. 2010) decline in response to fragmentation, whereas frugivorous and nectarivorous bats often increase (Sampaio et al. 2003; Delaval and Charles-Dominique 2006; Meyer and Kalko 2008a). In the Paleotropics, insectivorous bat species that roost in tree cavities or foliage are more vulnerable to fragmentation than are cave-roosting species (Struebig et al. 2008, 2009). At the assemblage level, studies that have compared fragmented and continuous forest in terms of species richness, diversity, and composition demonstrate inconsistent responses (Cosson et al. 1999; Schulze et al. 2000; Estrada and Coates-Estrada 2002; Faria 2006). Differences among sites with regard to fragmentation history and structural contrast between fragments and the surrounding matrix complicate the detection of general patterns. This may be a more important issue for the study of tropical bats compared to other taxonomic groups because of the wide range of dispersal abilities exhibited by chiropteran species.

\subsubsection{Area and Isolation Effects}

Early fragmentation studies generally emphasized the effects of area and isolation, reflecting the pervasive influence of island biogeographic theory (IBT, MacArthur and Wilson 1967) in ecology, while ignoring influences of the surrounding landscape matrix. This same pattern is also apparent within the fragmentation literature on tropical bats. Studies have found evidence for effects of both fragment area (Cosson et al. 1999; Struebig et al. 2008, 2011) and isolation (Estrada et al. 1993a; Meyer and Kalko 2008a, b) on population- and assemblage-level responses, whereas effects were weak or absent in others (Faria 2006; Pardini et al. 2009). Moreover, bat ensembles and species often respond differentially to fragment area or isolation, with responses of some taxa being particularly strong (Struebig et al. 2008; Estrada Villegas et al. 2010).

The relative importance of isolation versus area in shaping bat responses to fragmentation is governed by three main factors: the range of fragment sizes relative to isolation in the landscape, the history of landscape change (time since 
isolation, rate of change), and, probably most importantly, the type and quality of matrix habitats in which fragments are embedded. For instance, the high explanatory power of area relative to isolation reported by Struebig et al. (2008) likely reflects the low structural contrast between fragments and matrix (mostly rubber and oil palm plantations), limited range of isolation distances compared to area in the study system, and a possible time lag in the realization of isolation effects due to landscape change being fairly recent. In contrast, isolation rather than island area best predicted bat species richness and composition on Neotropical land-bridge islands (Meyer and Kalko 2008a) where fragments were surrounded by water.

The simplified dichotomous view of landscapes underlying IBT, albeit applicable in special cases (e.g., land-bridge islands), often fails to capture the influence that other land-cover types in the surrounding matrix can have and so may not be broadly applicable to most anthropogenically modified landscapes (Kupfer et al. 2006; Laurance 2008). After more than 40 years of research beyond the origins of IBT, it is now clear that for most animal taxa, including tropical bats, the majority of terrestrial habitat fragments are not islands in a homogeneous sea of inhospitable habitat. Indeed, island ecosystems support tropical bat biodiversity in fundamentally different ways compared to complex agricultural mosaic landscapes, the former adhering to IBT predictions of species loss, while countryside ecosystems are capable of maintaining high levels of species richness, evenness, and compositionally novel assemblages in human-made habitats (Mendenhall et al. 2014).

\subsubsection{Responses to Landscape Structure}

Fragmentation studies have increasingly shifted their focus from being largely patch-centered toward taking a broader landscape-scale approach, thus acknowledging the overriding importance of the matrix and the existence of gradients of habitat conditions and quality as crucial determinants of species responses (Kupfer et al. 2006; Driscoll et al. 2013; Cisneros et al. 2015). Such gradients are provided, for example, by mosaics of old-growth forest, successional habitat, and different forms of agriculture.

This paradigm shift is to some degree reflected within the more recent bat literature, as a growing number of studies have adopted matrix-inclusive approaches to studying fragmentation, although overall the number of studies is still small. In the broader literature, empirical evidence suggests widespread negative effects of habitat loss on many taxa (i.e., reduced abundance or density), whereas the effects of fragmentation per se are generally much weaker and may vary strongly in magnitude and direction of response (Fahrig 2003). In agreement with this, forest cover is a better predictor of bat assemblage characteristics (species richness or composition) than are measures of landscape configuration in Neotropical landbridge island systems (Meyer and Kalko 2008a; Henry et al. 2010). On the other hand, consistent responses to landscape composition or configuration at the assemblage level were harder to identify in studies conducted in fragmented Neotropical 
rain forest landscapes in which the matrix was a mix of anthropogenic land uses (Gorresen and Willig 2004; Klingbeil and Willig 2009, 2010; Cisneros et al. 2015). A difficulty facing bat fragmentation studies is that responses tend to be highly species specific, which is often overlooked by diversity metrics applied at the assemblage level (Klingbeil and Willig 2009). This might be more important in low-contrast systems, in which the quality of matrix habitats likely mitigates some of the negative effects of fragmentation on biological communities.

At the population level, available evidence suggests that tropical bats respond in complex ways to landscape composition (i.e., the amount of suitable habitat available across the patch types represented in the landscape) and configuration (Gorresen and Willig 2004; Henry et al. 2007b; Klingbeil and Willig 2009, 2010). For instance, Klingbeil and Willig $(2009,2010)$ found that, apart from being scale dependent (see Sect. 4.5.1.4), abundance responses by phyllostomid bats to landscape structure in the Amazon were highly species and ensemble specific, and differed between seasons. In the dry season, abundances of frugivores responded primarily to changes in forest cover (i.e., landscape composition), whereas configurational metrics elicited the strongest response in the wet season. Gleaning animalivores showed the opposite pattern, responding to landscape configuration in the dry season and to landscape composition in the wet season. Such divergent responses suggest an important role of spatiotemporal variation in the abundance and diversity of food resources (Klingbeil and Willig 2010; Cisneros et al. 2015). Together with seasonal differences in time and energy budgets linked to reproduction, these will affect species' foraging and movement behavior, and could lead to seasonal shifts in diet composition (Durant et al. 2013; Cisneros et al. 2015). Such links remain little explored, yet future research in this regard may prove highly informative.

\subsubsection{Spatial and Temporal Scale Dependence in Responses to Fragmentation}

The scale at which bat species perceive their environment in fragmented landscapes is likely influenced by spatiotemporal variation in the distribution of resources, as well as by species-specific differences in ecological traits such as diet, wing morphology, and movement behavior. For example, in a low-contrast fragmented system in Malaysia, the provision of large cave systems in the landscape provided clear population subsidies for cave-roosting bats, but also potentially masked the impact of forest fragmentation on this ensemble (Struebig et al. 2009). Consequently, single-scale assessments may be inadequate for capturing the complex interactions between species' ecology and landscape patterns (Gorresen and Willig 2004). While there is accumulating evidence of the diverse ways by which tropical bats respond to landscape structure, equally important is the increased recognition that the detection of such responses is also sensitive to the spatial scale at which the system is examined (Gorresen et al. 2005). 
Recent studies provide evidence for widespread scale dependence in associations between landscape metrics and bat responses at the assemblage, population, ensemble, and species levels (Gorresen and Willig 2004; Meyer and Kalko 2008a; Pinto and Keitt 2008; Klingbeil and Willig 2009, 2010; Henry et al. 2010; Cisneros et al. 2015). Pinto and Keitt (2008) quantified forest cover at a range of scales (buffers with radii from 50 to $2000 \mathrm{~m}$ ) and found positive associations with bat abundance, whereby the scale that elicited the strongest response was species specific. Differential species responses to forest cover in this case were best explained by interspecific variation in diet, body size, and home range size. Similarly, multiple species- and ensemble-specific abundance responses of phyllostomid bats to landscape characteristics at multiple focal scales (buffers with 1,3 , and $5 \mathrm{~km}$ radii) have been reported from moderately fragmented, lowland Amazonian forest (Klingbeil and Willig 2009) and highly fragmented Atlantic forest in Paraguay (Gorresen and Willig 2004). In both studies, species were demonstrated to interact with their environment simultaneously at a range of spatial scales. In the Amazon, a change in the focal scale of response occurred between dry and wet seasons, a finding which is likely linked to seasonal differences in food abundance and diversity as well as energetic constraints associated with reproduction (Klingbeil and Willig 2010; Cisneros et al. 2015). Scale dependence in response patterns has also been observed in landscapes with an aquatic matrix (Meyer and Kalko 2008a; Henry et al. 2010), suggesting that scale effects are ubiquitous and operate in fragmented landscapes across a broad range of matrix types.

Overall, such findings emphasize that multiscale approaches to determining the effects of landscape structure on tropical bats are essential. In agreement with recent findings for tropical birds (Banks-Leite et al. 2013), the available evidence suggests, however, that the extremely idiosyncratic responses of tropical bats to landscape structure make it difficult to identify any particular landscape predictor or spatial scale that performs best at predicting responses at the assemblage level.

Despite the general importance of a landscape-level perspective in the study of habitat fragmentation, patch characteristics remain important for patch-dependent species (Driscoll et al. 2013). However, fragmentation studies on tropical bats that have jointly assessed the relative contribution of patch- and landscape-scale variables for explaining response patterns are scarce. Meyer and Kalko (2008a) found that the relative importance of local- versus landscape-scale characteristics in explaining species richness and compositional patterns of phyllostomids on Panamanian land-bridge islands varied with spatial scale. At the patch scale, isolation distance from the mainland was the strongest predictor, whereas the proportion of forest cover in the surrounding landscape was the most prominent descriptor explaining variation in assemblage attributes at larger scales.

Although the importance of spatial scale and spatial variation in matrix quality have received some attention in the bat fragmentation literature, we know little about how species responses to fragmentation vary over time or how they are mediated by changes to the matrix. Across many human-modified landscapes in the tropics, secondary forest regrowth may reclaim once deforested 
land, for instance in response to the abandonment of agriculturally unproductive areas (Bobrowiec and Gribel 2010; Chazdon 2014). Matrix recovery following disturbance can alter responses of fragment biota that may be driven by temporal changes in resource availability and of permeability of the matrix to dispersal (Bissonette and Storch 2007; Driscoll et al. 2013). In this context, research at the Biological Dynamics of Forest Fragments Project in the Brazilian Amazon indicates strong divergence in phyllostomid bat assemblage structure, high levels of species turnover, and marked reorganization in the rank order of the most abundant species in response to changes in matrix quality and composition over 15 years (Meyer et al., unpublished data).

Time lags in the manifestation of species responses to fragmentation are ubiquitous and constitute an important temporal aspect to consider when studying fragmentation impacts (Ewers and Didham 2006a; Bissonette and Storch 2007), but so far have been rarely investigated in tropical bat studies. Notable exceptions are a series of studies conducted in the St. Eugène land-bridge island system in French Guiana, in which fragmentation effects prior to, and for several years after, fragmentation provided clear evidence for time lags in species loss (Cosson et al. 1999; Pons and Cosson 2002; Henry et al. 2010). These time lags occurred gradually over the course of ca. 10 years.

Future assessments of tropical bat responses to fragmentation (and other types of anthropogenic disturbance) should therefore address not only the spatial but also the temporal dimension of human impacts. This is particularly notable as long-term studies in intact habitats reveal tropical bat assemblages to be highly dynamic in space and time (Pech-Canche et al. 2011; Kingston 2013).

\subsubsection{Edge Effects}

Recent reviews concur that edge effects critically affect biodiversity in habitat fragments (Ewers and Didham 2006a; Fischer and Lindenmayer 2007; Laurance et al. 2011). However, responses of tropical bats to habitat edges remain understudied, particularly in the Paleotropics. Current evidence from the Neotropics suggests that responses vary according to matrix contrast and land-use history, and are ensemble and species specific.

Several studies have modeled bat responses in relation to the amount and complexity of edge habitat, revealing that some tropical bats are sensitive to habitat edges (Gorresen and Willig 2004; Meyer and Kalko 2008a; Klingbeil and Willig 2009, 2010; Henry et al. 2010). While significant associations between species richness or composition with edge density have been found in fragmented systems with a water matrix (Meyer and Kalko 2008a), studies conducted in a low-contrast landscape did not detect significant edge-related responses at the assemblage level (Gorresen and Willig 2004; Klingbeil and Willig 2009, 2010). This again underlines the importance of matrix contrast in affecting species' edge sensitivity and also shows that, at least in landscapes with low-contrast edges, composite community measures such as species richness may fail to capture edge responses that may 
otherwise be evident at the species or ensemble level (Klingbeil and Willig 2009). At the population level, abundances of six frugivorous and gleaning animalivorous phyllostomid bat species in the Peruvian Amazon were positively related to edge density, whereby responses varied depending on spatial scale (Klingbeil and Willig 2009) and season (Klingbeil and Willig 2010). In contrast, in fragmented Atlantic forest, two frugivorous species exhibited negative responses to edge density (Gorresen and Willig 2004). The discrepancy in the direction of response may be explained by differences in the prevailing patterns of land conversion (smallvs. large-scale deforestation). A strong negative response of gleaning animalivores to edge cover was also found by Henry et al. (2010) in a land-bridge island system in French Guiana.

These studies indicate the sensitivity of phyllostomid bats to edges driven by changes in landscape configuration. However, quantifying the strength of edge effects requires explicit consideration of two distinct aspects: edge extent and edge magnitude. Edge extent is the distance over which a change in the response variable can be detected, and edge magnitude is the amplitude of the effect (Harper et al. 2005; Ewers and Didham 2006b). The few studies that have examined the magnitude of edge effects on tropical bats by comparing interior sites of large, mature forest stands and forest edges reported declines in phyllostomid richness, in landscape matrices of high (water; Meyer and Kalko 2008a) and low structural contrast (secondary forest and shade cacao plantations; Faria 2006). The pattern of reduced species richness at edges in the low-contrast system was mainly attributable to the decline of gleaning animalivorous species (Faria 2006; Pardini et al. 2009). Even though species composition did not significantly change between forest edge and interior, Meyer and Kalko (2008a) found that gleaning animalivorous bats exhibited a strong negative numerical response toward edges. In fact, edge sensitivity was identified as the species trait that best explained species vulnerability to fragmentation (Meyer et al. 2008). Similar to phyllostomids, aerial insectivorous bats in the same land-bridge island system had significantly lower species richness at edges compared to interiors. The two functional groups of narrow-space foragers and open-space bats responded differently to forest edges. Open-space foragers had higher abundance counts at edges, whereas those of forest species were not significantly altered (Estrada Villegas et al. 2010). Comparing general bat activity, Estrada et al. (2004) did not detect significant differences between continuous forest interiors and forest-pasture edges.

Only one study to date has tried to quantify the distance of edge influence for tropical bats. Delaval and Charles-Dominique (2006) captured phyllostomid bats along 3-km transects perpendicular to the edges of a road traversing primary forest in French Guiana. Capture rates along the transects were more than seven times higher than those at a control site, $150 \mathrm{~km}$ inside the primary forest block. Moreover, along the transects abundances decreased with increasing distance from the road edge, a pattern attributable to the proliferation of opportunistic frugivores such as Carollia perspicillata and Artibeus jamaicensis that exploit abundant food resources provided by young regrowth along road margins. Species richness decreased significantly with distance from the road edge, probably related to an 
influx of species from the open habitat into the edges. Species richness at edges was, however, not significantly greater than that in the control site that harbored seven species not present at road edges or along transects. Differences in rank abundance patterns between transects and control site provided further evidence that even narrow road clearings can alter bat assemblage structure over distances of at least $3 \mathrm{~km}$ into forest interiors.

Key research needs:

- Studies that try to disentangle the relative importance of habitat amount and habitat configuration in shaping species responses, in particular studies that identify portions of the gradient in habitat amount within which the effects of spatial arrangement become important, i.e., explicit tests of the "habitat threshold hypothesis" (Fahrig 2003).

- Research that addresses the relative tolerance of different species to changes in habitat configuration (see Villard and Metzger 2014).

- Studies that jointly assess the relative contribution of patch- and landscape-scale variables to explaining response patterns.

- Long-term investigations that address the effects of matrix transformation on bat species responses over time.

- More studies that quantify edge effects in terms of both magnitude and extent.

- Further research investigating how consistently species respond to habitat edges across a broad range of edge types to identify ecological traits correlated with and potentially driving edge sensitivity (Ries and Sisk 2010).

- Studies that try to disentangle edge and area effects (Fletcher et al. 2007; Banks-Leite et al. 2010).

\subsubsection{Logging}

Rain forests are selectively logged at 20 times the rate at which they are cleared (Asner et al. 2009), and large expanses (403 million ha) are officially designated for timber extraction (Blaser et al. 2011). Selective logging exposes vast areas to potentially detrimental edge effects (Broadbent et al. 2008) and may often be the precursor to complete deforestation (Asner et al. 2006). Yet, the impacts of selective logging on biodiversity depend critically on the harvest intensity (Asner et al. 2013; Burivalova et al. 2014) as well as the extraction techniques (Bicknell et al. 2014). Selective harvesting methods range from large-scale conventional extraction that can cause substantial loss in canopy cover and associated mortality of non-harvested trees, to reduced-impact logging (RIL), in which collateral damage is reduced as a result of improved planning and control of harvesting activities (Putz et al. 2008; Asner et al. 2013).

Recent meta-analyses indicate that selectively logged forests can retain a large proportion of the diversity of old-growth forest for a variety of taxa (Gibson et al. 2011; Putz et al. 2012) and the available evidence, though scant due to the 
low number of studies (Fig. 4.3a), largely supports this notion for tropical bats (Bicknell et al. 2014). At the assemblage level, selective logging appears to have little or no effect on bat species richness in the Neotropics (Ochoa 2000; Clarke et al. 2005a, b; Castro-Arellano et al. 2007). In contrast, compositional or structural differences between bat assemblages in logged and unlogged sites are more common, which suggests that if forests are unable to recover from logging disturbance, species losses may be detected in the long term (i.e., similar to time lags for fragmentation effects, see Sect. 4.5.1). Structural differences between bat assemblages in unlogged and logged forests are evident from changes in the proportional abundance of species within ensembles (Clarke et al. 2005a, b; Peters et al. 2006) and shifts in species rank distributions and dominance (Castro-Arellano et al. 2007). A consistent pattern emerging from Neotropical studies is that, similar to habitat fragmentation (see Sect. 4.5.1), selective logging appears to adversely affect the abundance of gleaning animalivorous phyllostomids, whereas frugivorous and nectarivorous species tend to increase in abundance (Ochoa 2000; Clarke et al. 2005a, b; Peters et al. 2006; Presley et al. 2008).

In a study in Trinidad, Clarke et al. (2005a) found that the magnitude of change in species composition is linked to the intensity of timber harvesting. Comparing a continuous logging system with few harvest controls (open range [OR] system) to a polycyclic, selective system that incorporated stricter controls on felling (periodic block [PB] system), the study demonstrated that PB-managed sites resembled undisturbed primary forest much more closely in bat species composition and abundance than did OR forest. Despite structural changes associated with PB management, bat assemblages in such well-managed forest stands had great potential for recovery to near predisturbance levels (Clarke et al. 2005b). The number of years post-logging was positively correlated with the number and abundance of species of gleaning animalivores but not frugivores, whereas the proportional abundance of the dominant frugivore decreased with forest recovery. Together, these findings suggest that PB or similar low-intensity selective management systems may be compatible with the conservation of bat diversity. Unfortunately, similar studies that evaluate responses of tropical bats to different management systems or across a series of logged sites of different ages within the same general study landscape are lacking.

Short-term population-level responses of phyllostomid bats to RIL in Amazonia were idiosyncratic (Castro-Arellano et al. 2007) and RIL sites had reduced species richness, linked to the local absence of rare species from logged forest, whereas the populations of common species remained unaffected (Presley et al. 2008). As argued by Presley et al. (2008), landscape context may be important in mediating the effects of RIL on bats, and for this harvesting practice to be sustainable, it may be essential that RIL blocks be located in close proximity to undisturbed forest to facilitate rescue effects that can mitigate the negative impacts of RIL on rare species. Furthermore, due to the short post-harvest interval ( $<42$ months) in both studies, the observed responses may be short term (Castro-Arellano et al. 2007; Presley et al. 2008), stressing the necessity for longer-term evaluations of logging impacts. 
In the only logging effect study on African bats, Monadjem et al. (2010), using acoustic sampling, found no significant differences in activity levels between primary and logged forests in Uganda for the insectivorous Neoromicia nana. Elsewhere in the Paleotropics, early studies reported higher species richness, diversity, and abundance in unlogged compared to selectively logged forest in Malaysia (Zubaid 1993) and profound changes in species composition due to logging in Sumatra (Danielsen and Heegaard 1995). However, in addition to having small sample sizes, these studies employed only mist nets, which are ineffective at capturing the numerous insectivorous species that dominate Paleotropical bat assemblages (Kingston 2013). Conclusions based on these studies alone should therefore be interpreted with caution. More recent studies in Southeast Asia have employed larger sampling effort and harp traps, which are adequate for sampling forest interior insectivores. In peninsular Malaysia, a comparison of forest reserves and adjacent logged-over forests $>30$ years post-extraction showed little overall difference in assemblage composition (Christine et al. 2013). In nearly all site comparisons, species richness and abundances were higher in logged forest. However, certain tree- or foliage-roosting species were only captured inside forest reserves, suggesting that forest reserves embedded in a matrix of production forest could play an important role as reservoirs to restock logged forest and to maintain populations of disturbance-sensitive species (Christine et al. 2013).

Logging effects may multiply spatially and temporally as a result of multiple harvesting cycles (Lindenmayer and Laurance 2012). However, only recently have researchers examined the impacts of multiple rounds of extraction. One such study examined bat assemblages on Borneo across a disturbance gradient ranging from old-growth to twice-logged to repeatedly logged forest (Struebig et al. 2013). Logging had little effect on bat species richness, even in heavily degraded forest that had been logged multiple times, corroborating research on other taxa in the region (Edwards et al. 2011). Changes in insectivorous bat assemblage structure and abundance between old-growth and repeatedly logged forest were nonetheless evident and degraded sites that were characterized by a low, open canopy harbored a depauperate bat fauna. Canopy height was an important determinant of assemblage change across the disturbance gradient, as was the availability of tree cavities for forest-roosting taxa. By quantifying microhabitat over the gradient, the study revealed that post-logging recovery of assemblages could be enhanced via restoration investments in canopy cover and tree cavity availability. Moreover, cave-dwelling hipposiderid and rhinolophid bats were less abundant in repeatedly logged sites, in line with findings from a study in Vietnamese karst forests in which these taxa were also less abundant in logged than in primary forest (Furey et al. 2010).

A key theme emerging from the recent logging effect literature is the potential confounding issue of spatial pseudoreplication in study design, a problem whereby study sites in continuous forest stands are inappropriately treated as independent replicates (Ramage et al. 2013). The most effective way to overcome these problems is to sample the same forest sites before and after logging. The only batlogging study to have implemented such a robust Before-After-Control-Impact 
(BACI) design to date was undertaken in RIL forests in Guyana (Bicknell et al. 2015). Differences in bat assemblage structure before and after logging were relatively weak and varied substantially across study sites. Although three species were classified as indicators of disturbed or undisturbed forest, there were no clear changes in bat assemblages at control sites, indicating that overall responses could not be reliably attributed to logging.

In conclusion, given the paucity of studies available, it remains difficult to ascertain definitive responses of tropical bats to logging. The short-term effects appear to be relatively benign, especially in low-intensity extraction systems. Reported effects vary, largely owing to differences among studies with regard to the type of forest management system, and spatial and temporal variability in disturbance attributes, including time post-harvest.

Key research needs:

- Studies comparing bat responses between different forest management systems and across a range of spatial and temporal scales.

- More studies implementing BACI designs, as exemplified by Bicknell et al. (2015).

- Integration of logging disturbance into studies of forest fragmentation in order to distinguish true fragmentation responses from those of forest degradation.

\subsubsection{Secondary Forests and Succession}

The future of tropical biodiversity will critically depend on our ability to manage the large expanses of regenerating secondary forests (Chazdon et al. 2009; Chazdon 2014) that account for approximately half of the remaining area of tropical moist forests (Asner et al. 2009). Studies that have examined the conservation value of secondary forests for tropical bats are largely in line with assessments with regard to other tropical taxa (Barlow et al. 2007; Gardner et al. 2010) by suggesting that regenerating forests act as important repositories of bat biodiversity. Secondary forests are effective at conserving a subset of primary forest bat species richness (Louzada et al. 2010), but usually host assemblages that differ in structure and composition from those in mature forest (Faria 2006; Barlow et al. 2007).

Secondary successional vegetation in Neotropical humid forests represents important habitat for many frugivorous and nectarivorous phyllostomids (e.g., Carollia spp., Sturnira spp., Glossophaga spp.). These taxa become numerically dominant in secondary forests representing early to intermediate stages (Brosset et al. 1996; Castro-Luna et al. 2007a, b; Willig et al. 2007; de la PeñaCuéllar et al. 2012; Vleut et al. 2013). This pattern is likely attributable to an increase in the abundance, diversity, or quality of fruit and flower resources associated with early successional vegetation and emphasizes the fundamental importance of phyllostomid bats in the regeneration of tropical forests (Muscarella and Fleming 2007). In contrast, the abundance of frugivores was not elevated in earlier 
successional stages of tropical dry forest in Mexico (Avila-Cabadilla et al. 2009). This likely reflects distinct differences in the composition of early successional vegetation, and consequently resource scarcity, in tropical dry compared to wet forests. Pinto and Keitt (2008) found that the abundances of Sturnira spp. were positively associated with secondary forest cover, reflecting the species' preference for early successional vegetation. Conversely, Carollia spp. responded to forest cover that included both primary and secondary forests, implying that habitat connectivity may be more important than successional stage for populations in this genus. As with logged forests, these findings suggest species-specific responses to secondary vegetation linked to interspecific differences in diet, home range size, and body size. Contrary to the flexible responses observed for many frugivores and nectarivores, a large body of empirical evidence indicates that gleaning animalivorous phyllostomines are sensitive to forest degradation, as they are absent or occur at low abundance in secondary regrowth (Fenton et al. 1992; Brosset et al. 1996; Medellín et al. 2000; Faria 2006; Castro-Luna et al. 2007a, b; Mancina et al. 2007; Willig et al. 2007; Pardini et al. 2009; Bobrowiec and Gribel 2010; de la PeñaCuéllar et al. 2012; Vleut et al. 2012, 2013).

Some studies have detected a clear pattern of species richness increasing across successional gradients (Avila-Cabadilla et al. 2009; de la Peña-Cuéllar et al. 2012), but this pattern has not been evident in others (Castro-Luna et al. 2007a; Mancina et al. 2007). Nonetheless, for Neotropical wet and dry forests, floristically more diverse and structurally more complex habitats harbor greater taxonomic and functional richness than do early or intermediate stages of succession. Here, vegetation complexity appears to be an important factor shaping assemblage composition (Medellín et al. 2000; Avila-Cabadilla et al. 2009; Bobrowiec and Gribel 2010; Avila-Cabadilla et al. 2012; de la Peña-Cuéllar et al. 2012). Late successional forest stands often host many bat species not found in earlier stages, in particular rare taxa, and through succession, the number of species and ensembles increases for frugivorous, nectarivorous, and gleaning animalivorous taxa (AvilaCabadilla et al. 2009, 2012; de la Peña-Cuéllar et al. 2012). In tropical wet forest in Mexico, abundances of the most common bat species were associated positively or negatively with variation in canopy cover across successional stages, rather than with landscape attributes (Castro-Luna et al. 2007a). In contrast, a study in Mexican tropical dry forest found evidence for an important role of local (vegetation complexity) and landscape attributes (area and cover of different vegetation types) as determinants of variation in abundance, which were ensemble specific and scale dependent (Avila-Cabadilla et al. 2012). In Central Amazonia, gleaning animalivorous phyllostomid bats exhibited greater abundance and richness in Cecropia-dominated regrowth, whereas stenodermatine frugivores were more abundant in abandoned pastures and Vismia-dominated regrowth, demonstrating that different successional trajectories result from differences in land-use history (cutting versus cutting and burning) that lead to distinct differences in bat assemblage composition (Bobrowiec and Gribel 2010).

Despite the recovery potential of Neotropical bat assemblages during succession, the conservation value of secondary forests for bats critically hinges 
on landscape context and is maximized in mosaic landscapes in which patches of forest at different successional stages are located close to old-growth forest (Bobrowiec and Gribel 2010; Vleut et al. 2012).

Key research needs:

- Comprehensive assessments of the conservation value of secondary forests for bats in the Paleotropics, which are essentially lacking (but see Fukuda et al. 2009).

- Studies addressing the recovery potential of Paleotropical bat assemblages during secondary succession.

\subsubsection{Agroforestry Systems}

As agriculture and associated biodiversity losses continue to rise across the tropics, agroforestry systems have been advocated as biodiversity-friendly alternatives, capable of conserving biodiversity while enhancing rural livelihoods (Perfecto and Vandermeer 2008; Clough et al. 2011). Coffee (Coffea arabica, Coffea canephora) and cacao (Theobroma cacao) are the principal cash crops of many tropical countries (Donald 2004; Tscharntke et al. 2011) and are the primary examples in the bat literature (but see bat inventories of Sumatran rubber agroforests in Prasetyo et al. 2011). In traditional coffee and cacao agroforestry, these crops are commonly grown under a stratified canopy layer of a more or less diverse range of native shade tree species. Much of their potential for conservation derives from the fact that such traditional agroforestry systems resemble natural forest habitat in many structural aspects (Perfecto and Vandermeer 2008).

Empirical studies that have assessed the value of agroforests for tropical bats to date come almost exclusively from the Neotropics (Fig. 4.3a). Pineda et al. (2005) compared the bat fauna of Mexican cloud forest fragments and shade coffee plantations and found that both habitats had very similar species richness and composition, although there were changes in the species' rank order between habitats. Large frugivorous phyllostomids (Artibeus spp.) reached higher abundance in shade coffee than in the natural habitat, possibly as a result of increased food availability due to the cultivation of important fruit tree species alongside coffee, a management strategy that also favored the abundance and richness of fruit- and nectar-eating bats in coffee plantations elsewhere in Mexico (Castro-Luna and Galindo-González 2012a). Contrasting abundance responses for large Artibeus were found in another study in Mexico (Saldaña-Vázquez et al. 2010). Here, shade coffee plantations and disturbed cloud forest fragments did not differ in abundance levels and also had similar availability of food plants. On the other hand, abundances of Sturnira spp. were higher in forest fragments, probably linked to a decline in food resources for these small frugivores in the coffee plantations. This reduction in resources resulted from the pruning of understory vegetation and was reinforced by the effects of a resource-poor pasture matrix surrounding the forest fragments. 
Williams-Guillén and Perfecto (2010, 2011) investigated how bat diversity patterns in coffee agroforestry change with increasing management intensity. Phyllostomid bats maintained similar richness across management regimes, but showed significant declines in abundance across the intensification gradient, from forest fragments through low-management shade polyculture and commercial polyculture to high-management coffee monocultures (Williams-Guillén and Perfecto 2010). Compositional similarity differed significantly between fragments and coffee plantations of all management intensities, and between high-shade polycultures and low-shade monocultures. The proportions of large frugivores increased with management intensity, in line with Pineda et al.'s (2005) findings. Conversely, those of nectarivorous and gleaning animalivorous bats decreased, the latter being absent from intensively managed coffee monocultures. Both forest fragments and the diverse and structurally complex shade polyculture systems may provide adequate roosting and food resources to sustain high levels of phyllostomid diversity. This contrasts strongly with the situation in low-shade monocultures, which offer reduced feeding and roosting opportunities, and may consequently serve more as commuting than foraging habitat. This was also suggested in a study on non-phyllostomid aerial insectivorous bats in the same landscape, which reported reduced foraging activity in the most intensively managed monocultures (Williams-Guillén and Perfecto 2011). Both of the functional groups of aerial insectivores, forest and open-space foragers, had similar species richness across habitat types. The two groups, however, showed opposite responses with respect to activity levels and compositional similarity. Forest-adapted species differed in ensemble composition across the management gradient and responded negatively to agricultural intensification in terms of activity. For open-space foragers, reductions in shade tree diversity and cover did not manifest in compositional changes, but were associated with increased levels of overall activity, albeit not feeding activity.

Collectively, these studies demonstrate the high conservation value of structurally diverse shade coffee for bats, but less so of intensively managed systems. The former constitutes a permeable high-quality matrix, while intensive coffee monocultures represent poor matrix habitat (Numa et al. 2005). Landscape context, in particular the dominant matrix type, is an important modulator of how bat assemblages respond to agroforest management intensity. Forest fragments harbored significantly greater phyllostomid richness than did management systems when the landscape matrix was dominated by sun coffee, whereas richness was similar among habitats in a shade coffee matrix (Numa et al. 2005).

For cacao, studies show results similar to those for coffee, supporting the notion that traditional, structurally complex shade cacao plantations sustain high levels of bat diversity. Insights come from a series of studies conducted in the Atlantic forest region of Una, Brazil. Cacao agroforests in this region provide foraging and roosting habitat for members of all feeding ensembles, including forest-dependent gleaning animalivorous species (Pardini et al. 2009), primarily because of the structural complexity retained compared to intact forest (Faria et al. 2006). In fact, bat assemblages in shade cacao showed greater richness, diversity, and abundance 
than did those in nearby mature or secondary forest (Faria 2006; Faria and Baumgarten 2007; Pardini et al. 2009). However, shade cacao plantations per se may not provide adequate habitat conditions for forest-dwelling bats, as the proximity of shade cacao to forest remnants was a key determinant of species persistence. Bat assemblages in plantations isolated by more than $1 \mathrm{~km}$ from forest were characterized by low richness and diversity, with clear shifts in species dominance, suggesting a crucial role of native forest remnants as population sources (Faria and Baumgarten 2007). Isolating distance to forest was also an important factor influencing species richness and abundance in Mexican shade plantations (Estrada et al. 1993a). These plantations maintained diverse and structurally similar bat assemblages to those in remnants of native forest (Medellín et al. 2000; Estrada and Coates-Estrada 2001b). As for coffee (Numa et al. 2005), landscapes dominated by cacao agroforests and comprising reduced native forest cover may harbor impoverished bat assemblages (Faria et al. 2006; 2007), highlighting that landscape context generally plays a crucial role in determining bat species responses in tropical agroforestry landscapes, as it does for fragmented forest systems.

In conclusion, both coffee and cacao, when grown under a traditional shade regime, comprise a high-quality matrix that offers suitable conditions for maintaining diverse phyllostomid assemblages. These agroecosystems, in turn, benefit from pest control services provided by bats as has been shown for agroforests in the Neotropics (Williams-Guillén et al. 2008) and Southeast Asia (Maas et al. 2013) (see Chap. 6). Studies in cacao agroforestry at least in some cases entailed comparison between large tracts of mature forest and the agricultural system (Medellín et al. 2000; Faria 2006), but these important baseline data are lacking for studies in coffee agroforests.

Key research needs:

- Studies that assess response patterns for non-phyllostomid bats.

- Assessments of bat responses to cacao agroforestry intensification, especially in view of globally increasing levels of conversion of shade cacao systems into unshaded monocultures (Tscharntke et al. 2011).

- Linkages between levels of bat biodiversity and crop yields.

\subsubsection{Tree Plantations}

Given the extent to which forested land is being converted to tree plantations across much of the tropics (Gibbs et al. 2010), there have been surprisingly few studies investigating the value of these habitats for bats. Three systems dominate tree plantation mosaics in the tropics: fast-growing timbers for the paper/pulp industry (e.g., Acacia, Eucalyptus), rubber (Hevea brasiliensis), and, increasingly, oil palm (Elaeis guineensis). 
In a multitaxon assessment in Brazil, Barlow et al. (2007) found similar numbers of bat species in Eucalyptus plantations and secondary forests recovering from burning, but both habitats supported much lower richness than did unlogged forests. Bat assemblages in plantations were nested subsets of those in forests; approximately $11 \%$ of all species were shared between plantations and primary forest, $4 \%$ were shared with secondary forest, and $39 \%$ found in all habitats (Louzada et al. 2010). Nevertheless, three species (ca. $6 \%$ of total) were captured exclusively in Eucalyptus plantations.

A study in Brazilian Cerrado found lower species richness, diversity, and evenness of bat assemblages in Eucalyptus monocultures than in fragments of native Cerrado vegetation (Pina et al. 2013). Gleaning animalivorous phyllostomid bats were not captured in plantation forests. An earlier comparative study in Sumatra documented a distinct shift in bat assemblage structure in rubber and oil palm plantations, which supported only 13-25\% of the bat species richness found in forest (Danielsen and Heegaard 1995). However, more recent surveys have revealed additional species utilizing rubber plantations, especially those grown as agroforests or close to forest areas (Prasetyo et al. 2011). These studies point to an adverse response by bats to plantation development in both the New and Old World tropics. However, the extent to which these findings reflect true bat declines versus sampling bias (i.e., difficulties in capturing bats in open plantation habitats) is open to question. Tree plantations present a much more open habitat compared to forests, but can provide canopy structure similar to that in forest. This may present difficulties for capturing bats in these habitats, particularly in the Paleotropics, where much of the insectivorous bat fauna can only be captured in harp traps. Bat surveys in Sumatra and Borneo have resulted in extremely low capture rates for insectivorous species in oil palm plantations using mist nets and harp traps (Fukuda et al. 2009; Syamsi 2013), a finding that could reflect differential capture success in closed versus open habitats as well as true differences between habitats. Acoustic surveys could potentially contribute additional information concerning bat activity and the structure of bat assemblages in these habitats. The first insights from the Old World come from southern Thailand, where Phommexay et al. (2011) sampled bats in forest and neighboring rubber plantations using bat detectors, mist nets, and harp traps. Although diversity and overall bat activity were much lower in plantations than in forests, differences between the two habitat types were not as severe as indicated by capture-based surveys. Acoustic sampling in plantations detected less than half the number of bat species found in forest and fewer bat passes. Although bat activity was clearly reduced in plantations, a substantial number of feeding buzzes were detected, suggesting that bats were still foraging in this modified habitat.

Key research needs:

- Further studies, particularly those using acoustic methods, to accurately assess the conservation value of tree plantations for tropical bats. 


\subsubsection{Agriculture and Residual Tree Cover}

Agricultural encroachment and cropland expansion are key threats to biodiversity in tropical countries (Phalan et al. 2013). The dominant crop will determine the permeability of the agricultural matrix, the likelihood of species persistence, and ultimately whether sustainable configurations in human-modified landscapes emerge in which biodiversity conservation and food production can be reconciled (Melo et al. 2013).

Apart from several studies in agroforestry systems (see Sect. 4.5.4) and oil palm plantations (see Sect. 4.5.5), little research has examined responses of tropical bats to forest conversion into other agricultural land uses, or the value of residual vegetation in agricultural matrices (Fig. 4.3a). By far, most of the available evidence comes from studies in Mexico and Central American tropical wet and dry forests. These studies generally suggest that human-modified landscapes comprising a heterogeneous mosaic of different land- and tree-cover types can preserve species-rich bat assemblages (Estrada et al. 1993a, b, 2004; Medellín et al. 2000; Moreno and Halffter 2001; Estrada and Coates-Estrada 2002; Harvey et al. 2006; Medina et al. 2007; Barragan et al. 2010; Mendenhall et al. 2014). For instance, in a comparison of bat diversity in forest fragments, agricultural habitats, and live fences in Mexico, agricultural habitats contained $77 \%$ of the species recorded, whereby species richness declined with increasing distance from forest fragments (Estrada et al. 1993a). Certain frugivorous species (e.g., Carollia spp., Sturnira spp.) may become dominant in agricultural areas, whereas phyllostomine species are adversely affected by agriculture (Medellín et al. 2000). A similar pattern was found by Willig et al. (2007) in lowland Amazonian rain forest in Peru. Here, half of the frugivorous and nectarivorous species that responded consistently to habitat conversion reached highest abundances in agricultural areas, a response probably linked to the ample food resources provided by these habitats. Due to the presence of rare species not captured in forest, species richness in disturbed agricultural and early successional habitats was high compared to that in mature forest. However, the long-term persistence of most species likely still depends on the availability of forest (Willig et al. 2007). Moreover, these findings relate to smallscale habitat conversion and may not be generalizable to landscapes characterized by large-scale deforestation.

Knowledge of the conservation value of agricultural habitats for bats in the Old World is scant (see Chap. 6). In a study in Fiji (Luskin 2010), foraging densities of the Pacific flying fox, Pteropus tonganus, an important seed disperser were four times higher in agricultural habitats than in remnants of dry forest, illustrating a strong preference for foraging on abundant food resources in farmland. Resource subsidies provided by farmland were responsible for sustaining high abundances of the species despite severe deforestation across the region. Roosting sites, however, were restricted to native forest fragments, highlighting their importance for population persistence. Agricultural habitats provided important resources for some species of pteropodid bats in Borneo, as evidenced by high capture rates 
in orchards relative to forest habitats (Fukuda et al. 2009). Fukuda et al. (2009) suggest that some pteropodids in Southeast Asian dipterocarp forests, which are characterized by a supra-annual flowering and fruiting pattern, may augment food resources by feeding on cultivated plants during non-flowering periods when food supply in the forest is scarce. However, other fruit bat species were restricted to forest, suggesting that the value of agricultural land is species specific. Sedlock et al. (2008) reported that fewer species persist in mixed agricultural habitat than in tall secondary forest in the Philippines. Nevertheless, 19 of 26 species were present in agro-pastoral areas. Results from studies in the Paleotropics are thus largely congruent with those from the Neotropics in suggesting that agricultural habitats harbor considerable bat diversity and provide important foraging habitat for some fruit bat species.

Linear landscape elements (corridors of residual vegetation such as live fences or strips of riparian forest) and scattered trees, commonly found in Neotropical countryside landscapes, may enhance functional connectivity (Villard and Metzger 2014), and studies indicate that bats extensively use them (Estrada and CoatesEstrada 2001a; Galindo-González and Sosa 2003; Estrada et al. 2004; Harvey et al. 2006; Medina et al. 2007; Barragan et al. 2010). For instance, in agricultural landscapes in Nicaragua, riparian forests and live fences harbor greater bat species richness and abundance than do secondary forest and pastures with low tree cover (Harvey et al. 2006; Medina et al. 2007). Riparian forests constitute favorable habitats for foraging and roosting, particularly in tropical dry forest ecosystems, where they often have higher tree diversity and food availability compared to other types of cover (Estrada and Coates-Estrada 2001a; Harvey et al. 2006). Live fences and riparian corridors facilitate movement by bats across fragmented agricultural landscapes and may effectively reduce isolation between remnant forest patches, which, in turn, enhances species persistence at the landscape level. Similar to live fences, isolated pasture trees provide food and roosting opportunities for bats and act as important stepping stones for bat movement (Galindo-González and Sosa 2003), suggesting that they can render agro-pastoral landscapes more hospitable to bats and consequently deserve attention in conservation strategies. In contrast, studies concur that pastures are low-quality habitat for bats, likely as a consequence of resource scarcity (food, roosts) and elevated predation pressure (Estrada et al. 1993a, b, 2004; Harvey et al. 2006; Griscom et al. 2007; Medina et al. 2007).

\section{Key research needs:}

- In-depth studies in the Old World tropics that assess bat responses across a range of agricultural habitat types and landscape settings.

- Assessments of the value of residual tree cover in agricultural matrices for Paleotropical bats, particularly in Africa.

- Research addressing the effects of large-scale, commercial agriculture (e.g., cultivation of soybean, corn, sugarcane), which plays an increasingly significant role in driving deforestation in some tropical regions such as the Amazon. 


\subsection{Genetic Consequences}

Tropical taxa are generally underrepresented in landscape genetic studies (Storfer et al. 2010). Bats are no exception, as only few studies have assessed how they are affected by anthropogenic habitat loss and fragmentation at the genetic level (Fig. 4.3b). Meyer et al. (2009) studied populations of two Neotropical bats in fragments that were isolated by a water matrix and detected significant population differentiation that matched the species' relative mobility. In contrast to the more mobile canopy frugivore, Uroderma bilobatum, population subdivision in the understory frugivore, $C$. perspicillata, showed a significant effect of fragmentation and isolation by distance, as well as reduced genetic diversity on islands relative to mainland populations. Also employing mitochondrial DNA sequence data, Ripperger et al. (2013) documented small-scale genetic differentiation for another small understory frugivore, Dermanura watsoni, in fragments embedded in a matrix dominated by agriculture. Landscape connectivity as measured by the amount of suitable habitat surrounding forest patches was most strongly correlated with genetic variation when quantified within small-scale $(400 \mathrm{~m})$ landscape buffers, likely reflecting the reduced mobility of this species. Importantly, empirical levels of genetic diversity in fragments were best explained by past rather than present habitat conditions. Because anthropogenic habitat fragmentation is recent on evolutionary timescales, populations may not show immediate genetic responses to fragmentation, highlighting the importance of considering time lags in these scenarios.

In a microsatellite study of three codistributed insectivorous bat species in forest fragments in peninsular Malaysia, Struebig et al. (2011) observed area-related declines in genetic diversity in Kerivoula papillosa, the species that was most sensitive to fragmentation based on ecological characteristics (low vagility, low population density, tree-cavity-roosting habit). Based on the genetic-area relationship observed for $K$. papillosa, the authors estimated that preserving the genetic diversity of this species at levels similar to those of intact forest would require extensive areas ( $>10,000 \mathrm{ha})$, several times larger than necessary to maintain comparable levels of species richness. In view of the fact that most forest patches in heavily fragmented production landscapes across Southeast Asia are much smaller, it is evident that maintaining genetic diversity of the dozens of forest specialist species that exhibit trait combinations similar to those of $K$. papillosa constitutes a substantial conservation challenge (Struebig et al. 2011). Roosting ecology and social organization may generally be important predictors of genetic structuring in insectivorous Old World bats. Rossiter et al. (2012) found that less vagile, treeroosting species exhibit reduced gene flow, even across continuous intact rain forest, compared to more wide-ranging colonial cave-roosting species, indicating that the former should be disproportionately affected by landscape-scale habitat fragmentation.

Only weak genetic population subdivision was demonstrated for Artibeus lituratus, an abundant, highly mobile, and generalist frugivore, in a study in 
fragmented Atlantic forest (McCulloch et al. 2013). High levels of contemporary population connectivity in an abundant and widespread seed disperser like A. lituratus may buffer numerous plant species in Neotropical forests that rely on dispersal services of this bat species to counterbalance the negative impacts of deforestation.

In summary, the available evidence suggests, both in the New and in the Old World tropics, and irrespective of fragment-matrix contrast, that some bat species may be vulnerable to genetic erosion as a result of small-scale habitat fragmentation. Further, studies indicate that susceptibility in this context is linked to individual species traits such as mobility or roosting habit.

\section{Key research needs:}

- Increasing research on a broader range of species with different ecological and life-history traits, ideally using high-resolution genetic markers such as microsatellites or single-nucleotide polymorphisms (SNPs).

- Studies that quantify the extent to which frugivorous and nectarivorous bat species are capable of maintaining gene flow among plants in fragmented tropical landscapes.

\subsection{Behavioral Responses}

In addition to the direct effects on diversity and abundances, species' responses to anthropogenic habitat modification and disturbance can manifest as behavioral changes, which may include disruptions to species' dispersal, movement, activity patterns, and interspecific interactions (Fischer and Lindenmayer 2007). Few studies so far have addressed these issues for tropical bats (Fig. 3.3b).

Although a number of studies have reported movement distances and space use for a variety of tropical bat species (not reviewed here), few have explicitly addressed these phenomena in anthropogenically modified landscapes. Mark-recapture and radiotracking studies in the Neotropics suggest that in areas where landscape connectivity is relatively high, bats may regularly traverse open areas between forest fragments or between fragments and continuous forest. Evidence for interhabitat movements comes from landscapes with agricultural matrices (Estrada et al. 1993a; Estrada and Coates-Estrada 2002; Bianconi et al. 2006; Medina et al. 2007; Mendes et al. 2009; Trevelin et al. 2013) or from those with a more inhospitable aquatic matrix (Albrecht et al. 2007; Meyer and Kalko 2008a). Recapture data from a study in a fragmented landscape in Malaysia also indicate long-distance between-habitat movements for some cave-roosting species (Struebig et al. 2008). Whether a species is able to move over fragmented landscapes may be linked to the species' foraging ecology (Albrecht et al. 2007; Henry et al. 2007b). Overall, these studies were fundamental in determining the general capacity of tropical bats to move across human-modified habitats. However, they provide mostly circumstantial evidence and cannot establish whether 
anthropogenic disturbance elicits direct behavioral responses in bats that manifest as changes in movement distances or patterns of space use. Better insights into how habitat modification influences movement behavior can be gained through detailed radiotracking or long-term banding studies that compare movement patterns for species with different autecologies. Such studies, although difficult and costly to implement, would ideally compare continuous forest with fragments or other disturbed habitats.

Studies that have assessed behavioral changes to habitat modification in terms of effects on temporal activity patterns have followed such a rigorous approach. Disturbance-related changes in resource abundance, diversity, or predictability can be assumed to potentially alter temporal activity of species that exploit those resources (Presley et al. 2009b). Presley et al. (2009a) found no interspecific differences in activity patterns of eight abundant frugivorous bats in primary lowland Amazonian rain forest. However, for five species, activity patterns differed between primary or secondary forest and agricultural habitats, whereby bats in larger agricultural areas exhibited reduced crepuscular activity compared to those in undisturbed forest. Elsewhere in Amazonia, Castro-Arellano et al. (2009) detected no differences in activity levels for nectarivores and gleaning animalivores in response to RIL. Conversely, understory frugivores (Carollia spp.) decreased activity at dusk. Another study found reduced activity by some frugivores in small forest clearings created by tree removal, although the overall effects of RIL on activity patterns of frugivores were negligible (Presley et al. 2009b). In all cases, the curtailment of activity in open areas at twilight or during periods of high lunar illumination was best explained by increased predation risk (SaldañaVázquez and Munguía-Rosas 2013). Habitat modification and disturbance may consequently influence energy budgets of bats as they have less time available for foraging, with possible negative repercussions for their ability to meet daily energy requirements.

Human disturbance may also affect roosting behavior and roost site selection. In fragmented rain forest in Mexico, Evelyn and Stiles (2003) found that both sexes of cavity-roosting Sturnira lilium selected large-diameter trees in mature forest stands, as did females of the foliage-roosting Artibeus intermedius, whereas males of the latter species roosted in secondary forest. These findings underscore that preferences in terms of roosting and foraging habitat are not necessarily correlated and point to the importance of preserving mature forest patches in human-dominated landscapes for meeting the roosting requirements of tree-cavityroosting species.

Key research needs:

- More studies, particularly in the Paleotropics, that assess the extent to which human-driven habitat change affects bat behavior in terms of roosting and foraging ecology.

- Research that addresses how such behavioral changes translate into fitness consequences (e.g., in terms of survival, reproductive success, physiology) that may affect long-term population persistence. 


\subsection{Effects on Selected Species Interactions}

In recent years, bats have moved to the forefront of public attention, mostly as a result of accumulating evidence that they comprise important reservoir hosts for numerous zoonotic viruses (e.g., lyssaviruses, SARS, Ebola) that may pose a serious health risk to humans (Calisher et al. 2006; Hayman et al. 2013, Chap. 10). Recent studies have highlighted the urgency of gaining a better understanding of how habitat loss, land-use change and disturbance and an associated increase in bat-human interactions may, for instance, accelerate viral spillover (Peel et al. 2013). However, few studies to date have explored to what extent these stressors influence patterns of parasite and disease prevalence and transmission, as well as physiological stress responses in bats (Fig. 4.3b).

Cottontail et al. (2009) found that trypanosome prevalence in A. jamaicensis was significantly higher in fragmented sites than in continuous forest, linked to a loss of bat species richness and fragmentation-related changes in vegetation cover that may favor disease transmission. The negative relationship between trypanosome prevalence and bat species richness reflects the "dilution effect," i.e., a situation in which high host species richness reduces parasite transmission if vectors feed on multiple host species that vary in their ability to contract, amplify, or transmit the pathogen (Ostfeld and Keesing 2012). In contrast, prevalence of hemoparasitic nematodes (Litomosoides spp.) showed no significant difference among habitats, probably as a result of greater host specificity (Cottontail et al. 2009). In another study, fragmentation affected the physiological condition of A. obscurus, as evidenced by elevated hematocrit levels in forest fragments versus continuous forest, even though similar abundances in both habitats indicated a high degree of fragmentation tolerance. The opposite pattern was documented for A. jamaicensis, suggesting that abundance may in many instances be misleading as a metric of fragmentation sensitivity (Henry et al. 2007a). Pilosof et al. (2012) found a significant effect of anthropogenic disturbance on the abundance of ectoparasitic bat flies in three of four widespread Neotropical host bat species, whereby the direction of response differed among species. Species-specific roosting habits likely play a key role in mediating the effects of disturbance on parasite transmission. A study in Mexico found significantly lower prevalence of antirabic antibodies in non-hematophagous bats in disturbed agricultural areas $(22.7 \%)$ compared to relatively undisturbed dry forest sites $(51.9 \%)$, a pattern which may arise because of more frequent interspecies encounters in the undisturbed habitat (Salas-Rojas et al. 2004).

The important role of animalivorous, frugivorous, and nectarivorous bats in arthropod suppression, seed dispersal, and pollination in tropical ecosystems is widely acknowledged (Kunz et al. 2011). The degree to which such interactions are susceptible to habitat modification and disturbance is generally better understood for seed dispersal than for pollination or arthropod suppression. Mostly using fecal analysis or seed traps, numerous studies in various human-modified landscapes across the Neotropics have documented the quantity and diversity of 
seeds carried by bats (mostly Carollia spp., Sturnira spp., Artibeus spp.) into a diverse range of disturbed habitats including pastures, agricultural areas, coffee plantations, and secondary forests (Medellín and Gaona 1999; Galindo-González et al. 2000; García et al. 2000; Aguiar and Marinho-Filho 2007; Hanson et al. 2007; Wieland et al. 2011; Castro-Luna and Galindo-González 2012b; GarcíaEstrada et al. 2012; García-Morales et al. 2012; Gorchov et al. 2013). Voigt et al. (2012) showed that bats of the genus Carollia were likely to carry seeds from midsuccessional forest into adjacent primary forest, suggesting that directionality of seed transfer between disturbed areas and undisturbed forest may change with forest recovery. Isolated fig trees in abandoned pastures are attractive for many frugivores and may function as regeneration nuclei that effectively facilitate forest recovery (Guevara et al. 2004). Overall, these studies provide little evidence for major disruptions of seed dispersal mutualisms in response to habitat fragmentation and disturbance, although minor effects were detectable. For instance, small frugivorous bats disperse fewer large seeds in small, disturbed compared to large, undisturbed forest patches (Melo et al. 2009), suggesting a negative impact of disturbance on the dispersal of larger-seeded trees. Although Old World fruit bats in some areas may disperse seeds of early successional species (Hamann and Curio 1999), seed input into deforested or degraded areas tends to be low in humanmodified landscapes in the Paleotropics (Duncan and Chapman 1999; Ingle 2003). Pteropodids generally play a much less significant role as dispersers of early successional plants compared to phyllostomids, but are important dispersers of late successional canopy trees (Muscarella and Fleming 2007). How habitat modification affects seed dispersal of large-seeded canopy trees by pteropodid fruit bats in Paleotropical forests requires further detailed study.

Research in fragmented Central American dry forest ecosystems found a decline in flower visitation rates, number of pollen grains deposited, and fruit set of certain bombacaceous tree species, suggesting that habitat disruption can impair the pollination services of nectarivorous phyllostomids, with negative consequences for plant reproductive success (Stoner et al. 2002; Quesada et al. 2003). However, effects were dependent on plant species (Quesada et al. 2004), making general predictions regarding the effects of habitat modification on the disruption of bat pollination difficult. Through its influence on bat foraging behavior, habitat disturbance may also limit pollen exchange between trees, leading to higher progeny relatedness in isolated trees relative to those in undisturbed forest (Quesada et al. 2013). In a fragmented landscape in tropical Australia, common blossom bats (Syconycteris australis) were high-quality pollinators of the rain forest tree Syzygium cormiflorum, as inferred based on pollen loads, visitation rates, and movement patterns (Law and Lean 1999). Nectarivorous bats often attain higher abundance in response to anthropogenic disturbance (see Sect. 4.5), suggesting that provisioning of pollination services may potentially be resistant and resilient to environmental perturbation. 
Key research needs:

- Detailed studies that address the causal links between human-induced landscape change and bat physiological and immune responses, as well as disease susceptibility.

- Studies, particularly in the Paleotropics, that document the full dispersal cycle-from seed deposition through germination, seedling establishment, and recruitment-and how it is affected by habitat alteration.

- Further studies across a range of pollinator and plant species, as well as fragmented landscapes with different degrees of connectivity, to directly relate behavior and movement of pollinators with reproductive success and gene flow of trees.

- Studies that address the extent to which arthropod suppression services are affected by more intensive forms of habitat alteration and disturbance such as those associated with secondary forests, tree plantations, or cropland (see Wanger et al. 2014).

\subsection{General Conclusions and Future Research Directions}

As a consequence of a rapid increase in the annual number of publications over the past quarter century, ecological understanding has broadened and deepened concerning the influence of land conversion and habitat fragmentation on tropical bats at the level of populations, ensembles, and assemblages. Nonetheless, large geographic and taxonomic biases characterize current understanding.

Although many studies document that human-induced changes in land use alter bat species abundances and taxonomic dimension of biodiversity, surprisingly few studies have explored how these changes manifest with regard to genetic, behavioral, physiological, or disease-related phenomena. Similarly, little is known about the way in which land-use change affects functional or phylogenetic dimensions of biodiversity (but see Cisneros et al. 2015). Studies generally are not conducted in a spatially explicit manner (Fig. 4.4a), so multiscale (e.g., alpha, beta, and gamma diversities) or cross-scale interactions cannot be explored fully, and conclusions must be tempered in the absence of a more integrated understanding of the role of unmodified habitat in rescuing local populations from extinction. Key insights from landscape-scale studies comprise the species- and ensemble-specific nature of responses, as well as their dependence on spatial scale. The most fundamental developments include the recognition that habitat fragmentation is a complex process involving the nature of patches (i.e., landscape composition and configuration), as well as the nature of the matrix that arises as a consequence of direct, human modifications of the landscape (Fig. 4.4b). Finally, the consequences of changes in the bat fauna from habitat conversion and fragmentation have not been 
(a) APPROACHES THAT ARE NOT SPATIOTEMPORALLY EXPLICIT Not Sensitive to Cross-Scale Interactions

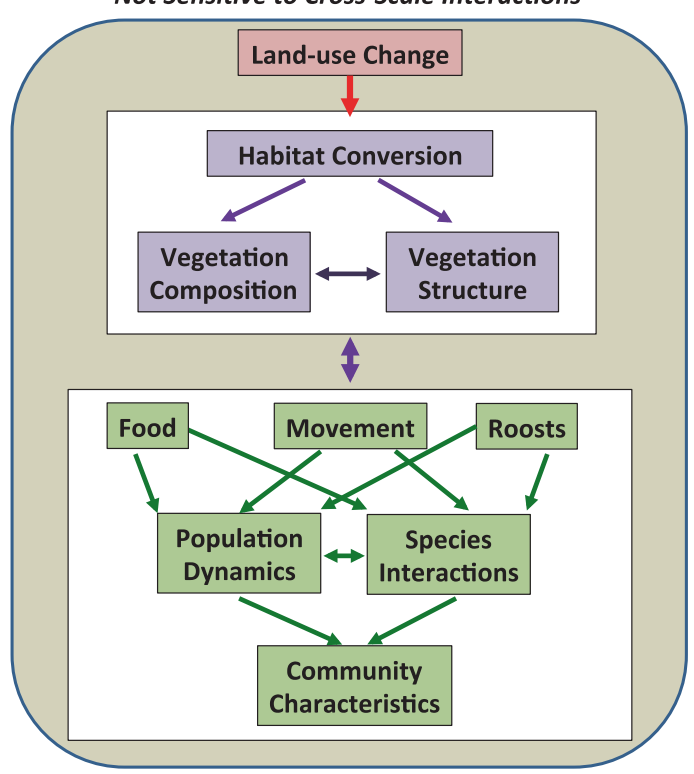

(b) APPROACHES THAT ARE SPATIOTEMPORALLY EXPLICIT Sensitive to Cross-Scale Interactions

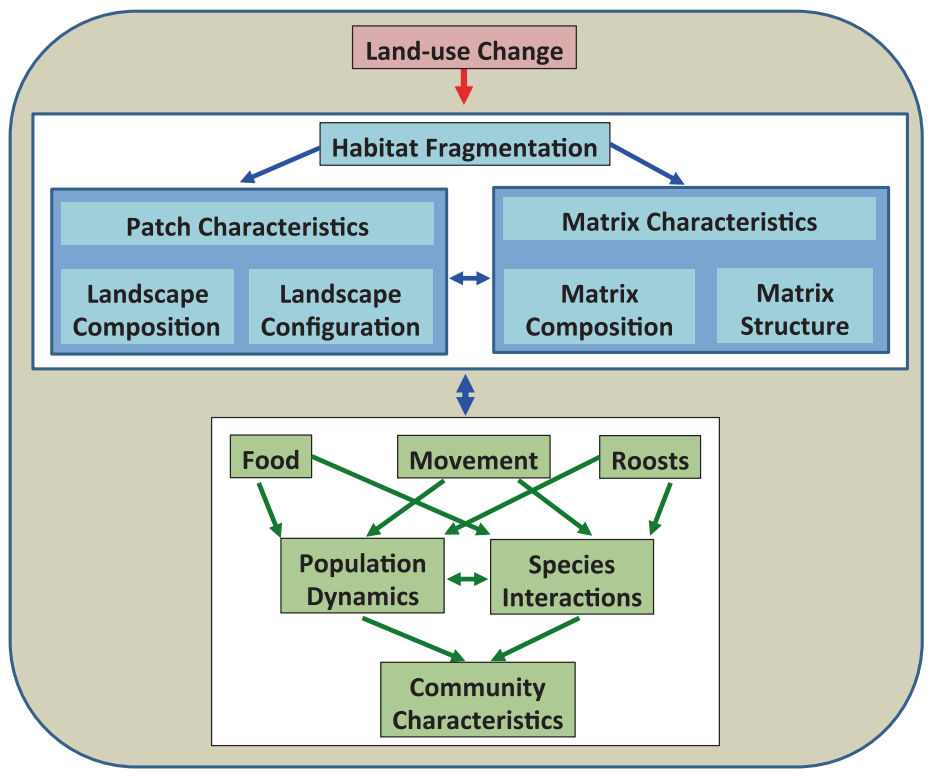


Fig. 4.4 Two conceptual models that indicate the pathways whereby land-use changes affect bats in ways that $\mathbf{a}$ are not spatiotemporally explicit or $\mathbf{b}$ are spatiotemporally explicit. In both scenarios, effects of land-use change are mediated by alterations in the vegetation, but the underlying mechanisms differ (contrast the purple boxes with the blue boxes). Nonetheless, populations and assemblages of bats respond via similar mechanisms associated with feeding, roosting, and movement opportunities (green boxes). Generally, studies that explore the effects of habitat conversion (e.g., effects of logging or agriculture) on bats are not spatially explicit. Land-use change is reflected in habitat conversion that directly alters the composition and structure of the vegetation, with effects on the abundance and distribution of food resources or roosts, and the existence of "flyways" whereby bats navigate through the forest. In concert, these three characteristics affect the population dynamics of different bat species and the interaction likelihoods among species (e.g., bat species, other animal species, and disease-causing microorganisms). As a consequence, changes in bat species abundance distributions (e.g., richness, evenness, dominance, diversity, rarity) emerge with cascading effects on the vegetation as a consequence of altered seed dispersal, pollination, or regulation of insect herbivores. Generally, studies of habitat fragmentation are spatially explicit and explore how land-use change affects a focal habitat type (e.g., forest) by creating a network of patches embedded in a matrix of human-modified habitats. Such studies have the potential to explore how patch characteristics (e.g., landscape composition and configuration of forest patches) as well as matrix characteristics (e.g., structural or compositional attributes of the converted land) interact to affect the bat fauna. See text for additional details

quantified with regard to the maintenance of vital ecosystem processes or services. Clearly, we are still far from a comprehensive understanding of how tropical bats respond to habitat modification.

To advance ecological understanding, we have highlighted a number of more specific research needs across all themes in this chapter. We further stress the following key research directions as particularly worthy of pursuit, many of which have been summarized in different context for mammals in general (e.g., Willig 2001).

1. Geographic and taxonomic biases toward the Neotropics and a focus on just one bat family, Phyllostomidae, need to be overcome. Although research efforts in Southeast Asia are gaining momentum (Kingston 2013), Africa deserves greatly intensified research activities. As technological advances now make acoustic sampling of aerial insectivorous bats increasingly time- and costefficient, this ensemble should regularly be targeted in ecological research, including environmental impact assessments.

2. Research should be broadened to encompass the full spectrum of possible responses at the level of populations, ensembles, assemblages, and metacommunities. Novel mechanistic insights could be gained by studies that assess behavioral responses to particular types of habitat conversion or habitat fragmentation. Similarly, studies are needed to investigate physiological and immune responses, as well as disease susceptibility across a broad range of host and vector species. A better understanding of the genetic effects on bats from habitat modification requires integrated research on a suite of different species that explore the link between patterns of genetic variation and species' ecological and life-history traits. In general, the way in which species traits and 
environmental factors interact to shape species responses to landscape change is unclear, as trait-based approaches have been rare (but see Farneda et al. 2015). Understanding how functional and phylogenetic biodiversity changes during habitat conversion and secondary succession is investigated rarely and remains poorly understood. Much also remains to be learned about how habitat disruption and modification affect the provisioning of critical ecosystem services, especially flower pollination and arthropod suppression.

3. Multiscale studies provide a more comprehensive understanding of pattern-process relationships in heterogeneous human-modified landscapes than do single-scale assessments. Future research should address bat responses to landscape change with respect to both spatial and temporal dimensions. Considerable progress in the field could be made by directing greater research effort and resources toward long-term studies that are capable of unveiling novel insights, which are hard or impossible to obtain from short-term, crosssectional studies (cf. Lindenmayer et al. 2011). Studies currently underway at the Biological Dynamics of Forest Fragments Project (BDFFP) in Brazil (Meyer et al, unpublished data) or at the Stability of Altered Forest Ecosystems (SAFE) Project in Borneo (e.g., Struebig et al. 2013) provide examples of first efforts in this direction. The need for broader geographic coverage notwithstanding, directing more research to well-studied systems or long-term study sites, allows the responses of bats to land-use change to be compared to those of other taxa (e.g., Barlow et al. 2007; Bicknell et al. 2015; Ewers et al. 2015).

4. We stress the importance of robust study designs for assessing faunal responses to habitat alteration. Studies should have adequate replication (cf. Ramage et al. 2013) and involve controls or reference sites. Lack of controls is an important shortcoming of many of the reviewed studies, which often focused on comparisons of different types of disturbed habitats. This clearly limits their ability to ascribe observed effects to disturbance. We echo Kingston's (2013) call for studies to collect predisturbance, baseline information whenever possible, given that tropical bat assemblages exhibit considerable spatiotemporal variability even in unmodified habitats. In this context, Before-After-ControlImpact designs (e.g., Bicknell et al. 2015), in which sites affected by human disturbance are compared with undisturbed reference sites, both before and after impact, enhance inferential strength (Smith 2013), and add scientific rigor to future assessments of the effects of habitat modification on tropical bats.

Finally, an improved ecological understanding of bat responses to land-use change will be of little use to society unless it can be translated into improved management practices that ensure their long-term conservation and provision of critical ecosystem services. Across all themes in this chapter, we urge bat researchers to apply more of their science to policy and management questions. Examples of such applications include the effectiveness of specific management practices (e.g., farming intensity, cutting cycles) and mitigation measures (e.g., riparian conservation set-asides, artificial roosts). 
Acknowledgments We would like to thank the editors for the invitation to contribute to this volume and Brock Fenton and Jorge Galindo-González for helpful comments on the manuscript.

Open Access This chapter is distributed under the terms of the Creative Commons Attribution Noncommercial License, which permits any noncommercial use, distribution, and reproduction in any medium, provided the original author(s) and source are credited.

\section{References}

\section{*Studies considered in our systematic review}

Aguiar LMS, Marinho-Filho J (2007) Bat frugivory in a remnant of Southeastern Brazilian Atlantic forest. Acta Chiropt 9:251-260*

Albrecht L, Meyer CFJ, Kalko EKV (2007) Differential mobility in two small phyllostomid bats, Artibeus watsoni and Micronycteris microtis, in a fragmented Neotropical landscape. Acta Theriol 52:141-149*

Asner GP, Broadbent EN, Oliveira PJC et al (2006) Condition and fate of logged forests in the Brazilian Amazon. Proc Natl Acad Sci 103:12947-12950

Asner GP, Keller M, Lentini M et al (2013) Selective logging and its relation to deforestation. In: Keller M, Bustamante M, Gash J, Silva Dias P (eds) Amazonia and Global Change. American Geophysical Union, Washington, D.C., pp 25-42

Asner GP, Rudel TK, Aide TM et al (2009) A contemporary assessment of change in humid tropical forests. Conserv Biol 23:1386-1395

Avila-Cabadilla LD, Sanchez-Azofeifa GA, Stoner KE et al (2012) Local and landscape factors determining occurrence of phyllostomid bats in tropical secondary forests. PLoS ONE 7:e35228*

Avila-Cabadilla LD, Stoner KE, Henry M et al (2009) Composition, structure and diversity of phyllostomid bat assemblages in different successional stages of a tropical dry forest. For Ecol Manage 258:986-996*

Banks-Leite C, Ewers RM, Metzger J-P (2010) Edge effects as the principal cause of area effects on birds in fragmented secondary forest. Oikos 119:918-926

Banks-Leite C, Ewers RM, Metzger J-P (2013) The confounded effects of habitat disturbance at the local, patch and landscape scale on understorey birds of the Atlantic Forest: Implications for the development of landscape-based indicators. Ecol Indic 31:82-88

Barlow J, Gardner TA, Araujo IS et al (2007) Quantifying the biodiversity value of tropical primary, secondary and plantation forest. Proc Natl Acad Sci USA 104:18555-18560*

Barragan F, Lorenzo C, Moron A et al (2010) Bat and rodent diversity in a fragmented landscape on the Isthmus of Tehuantepec, Oaxaca, Mexico. Trop Conserv Sci 3:1-16*

Bianconi GV, Mikich SB, Pedro WA (2006) Movements of bats (Mammalia, Chiroptera) in Atlantic Forest remnants in southern Brazil. Rev Bras Zool 23:1199-1206*

Bicknell JE, Struebig MJ, Edwards DP et al (2014) Improved timber harvest techniques maintain biodiversity in tropical forests. Curr Biol 24:R1119-R1120

Bicknell JE, Struebig MJ, Davies ZG (2015) Reconciling timber extraction with biodiversity conservation in tropical forests using Reduced-Impact Logging. J Appl Ecol 52:379-388

Bissonette JA, Storch I (2007) Temporal dimensions of landscape ecology: wildlife responses to variable resources. Springer, New York

Blaser J, Sarre A, Poore D et al (2011) Status of tropical forest management. ITTO technical series no. 38. International Tropical Timber Organization, Yokohama, Japan

Bobrowiec PED, Gribel R (2010) Effects of different secondary vegetation types on bat community composition in Central Amazonia, Brasil. Anim Conserv 13:204-216*

Broadbent EN, Asner GP, Keller M et al (2008) Forest fragmentation and edge effects from deforestation and selective logging in the Brazilian Amazon. Biol Conserv 141:1745-1757 
Brosset A, Charles-Dominique P, Cockle A et al (1996) Bat communities and deforestation in French Guiana. Can J Zool 74:1974-1982*

Burivalova Z, Şekercioğlu ÇH, Koh LP (2014) Thresholds of logging intensity to maintain tropical forest biodiversity. Curr Biol 24:1893-1898

Calisher CH, Childs JE, Field HE et al (2006) Bats: important reservoir hosts of emerging viruses. Clin Microbiol Rev 19:531-545

Castro-Arellano I, Presley SJ, Nelio Saldanha L et al (2007) Effects of reduced impact logging on bat biodiversity in terra firme forest of lowland Amazonia. Biol Conserv 138:269-285*

Castro-Arellano I, Presley SJ, Willig MR et al (2009) Reduced-impact logging and temporal activity of understorey bats in lowland Amazonia. Biol Conserv 142:2131-2139*

Castro-Luna AA, Galindo-González J (2012a) Enriching agroecosystems with fruit-producing tree species favors the abundance and richness of frugivorous and nectarivorous bats in Veracruz, Mexico. Mamm Biol 77:32-40*

Castro-Luna AA, Galindo-González J (2012b) Seed dispersal by phyllostomid bats in two contrasting vegetation types in a Mesoamerican reserve. Acta Chiropt 14:133-142*

Castro-Luna AA, Sosa VJ, Castillo-Campos G (2007a) Bat diversity and abundance associated with the degree of secondary succession in a tropical forest mosaic in south-eastern Mexico. Anim Conserv 10:219-228*

Castro-Luna AA, Sosa VJ, Castillo-Campos G (2007b) Quantifying phyllostomid bats at different taxonomic levels as ecological indicators in a disturbed tropical forest. Acta Chiropt 9:219-228*

Chazdon RL (2014) Second growth: The promise of tropical forest regeneration in an age of deforestation. University of Chicago Press, Chicago

Chazdon RL, Peres CA, Dent D et al (2009) The potential for species conservation in tropical secondary forests. Conserv Biol 23:1406-1417

Christine LJ, Fletcher C, Abd Rahman K (2013) Spatial effects of virgin jungle reserves (VJR) on the community of insectivorous bats in Peninsular Malaysia. J Trop For Sci 25:118-130*

Cisneros LM, Fagan ME, Willig MR (2015) Effects of human-modified landscapes on taxonomic, functional, and phylogenetic dimensions of bat biodiversity. Divers Distrib 21:523-533 *

Clarke FM, Pio DV, Racey PA (2005a) A comparison of logging systems and bat diversity in the Neotropics. Conserv Biol 19:1194-1204*

Clarke FM, Rostant LV, Racey PA (2005b) Life after logging: post-logging recovery of a neotropical bat community. J Appl Ecol 42:409-420*

Clough Y, Barkmann J, Juhrbandt J et al (2011) Combining high biodiversity with high yields in tropical agroforests. Proc Natl Acad Sci 108:8311-8316

Collinge SK (2009) Ecology of fragmented landscapes. Johns Hopkins University Press, Baltimore

Cosson J-F, Pons J-M, Masson D (1999) Effects of forest fragmentation on frugivorous and nectarivorous bats in French Guiana. J Trop Ecol 15:515-534*

Cottontail VM, Wellinghausen N, Kalko EKV (2009) Habitat fragmentation and haemoparasites in the common fruit bat, Artibeus jamaicensis (Phyllostomidae) in a tropical lowland forest in Panama. Parasitology 136:1133-1145*

Cunto GC, Bernard E (2012) Neotropical bats as indicators of environmental disturbance: what is the emerging message? Acta Chiropt 14:143-151

Danielsen F, Heegaard M (1995) Impact of logging and plantation development on species diversity: a case study from Sumatra. In: Sandbukt O (ed) Management of tropical forests: towards an integrated perspective. Centre for Development and the Environment, University of Oslo*

de la Peña-Cuéllar E, Stoner KE, Avila-Cabadilla LD et al (2012) Phyllostomid bat assemblages in different successional stages of tropical rain forest in Chiapas, Mexico. Biodivers Conserv 21:1381-1397* 
DeFries RS, Rudel T, Uriarte M et al (2010) Deforestation driven by urban population growth and agricultural trade in the twenty-first century. Nat Geosci 3:178-181

Delaval M, Charles-Dominique P (2006) Edge effects on frugivorous and nectarivorous bat communities in a neotropical primary forest in French Guiana. Rev Ecol-Terre Vie 61:343-352*

Dent DH, Wright SJ (2009) The future of tropical species in secondary forests: a quantitative review. Biol Conserv 142:2833-2843

Didham RK (2010) Ecological consequences of habitat fragmentation. ELS. Wiley, London

Donald PF (2004) Biodiversity impacts of some agricultural commodity production systems. Conserv Biol 18:17-38

Driscoll DA, Banks SC, Barton PS et al (2013) Conceptual domain of the matrix in fragmented landscapes. Trends Ecol Evol 28:605-613

Duncan RS, Chapman CA (1999) Seed dispersal and potential forest succession in abandoned agriculture in tropical Africa. Ecol Appl 9:998-1008*

Durant KA, Hall RW, Cisneros LM et al (2013) Reproductive phenologies of phyllostomid bats in Costa Rica. J Mammal 94:1438-1448

Edwards DP, Larsen TH, Docherty TDS et al (2011) Degraded lands worth protecting: the biological importance of Southeast Asia's repeatedly logged forests. Proc R Soc B 278:82-90

Estrada A, Coates-Estrada R (2001a) Bat species richness in live fences and in corridors of residual rain forest vegetation at Los Tuxtlas, Mexico. Ecography 24:94-102. *

Estrada A, Coates-Estrada R (2001b) Species composition and reproductive phenology of bats in a tropical landscape at Los Tuxtlas, Mexico. J Trop Ecol 17:627-646*

Estrada A, Coates-Estrada R (2002) Bats in continuous forest, forest fragments and in an agricultural mosaic habitat-island at Los Tuxtlas, Mexico. Biol Conserv 103:237-245*

Estrada A, Coates-Estrada R, Meritt J, Dennis (1993a) Bat species richness and abundance in tropical rain forest fragments and in agricultural habitats at Los Tuxtlas, Mexico. Ecography 16:309-318*

Estrada A, Coates-Estrada R, Meritt Jr. D et al (1993b) Patterns of frugivore richness and abundance in forest islands and agricultural habitats at Los Tuxlas, Mexico. Vegetatio 107/108:245-257*

Estrada A, Jiménez C, Rivera A et al (2004) General bat activity measured with an ultrasound detector in a fragmented tropical landscape in Los Tuxtlas, Mexico. Anim Biodivers Conserv 27:1-9*

Estrada Villegas S, Meyer CFJ, Kalko EKV (2010) Effects of forest fragmentation on aerial insectivorous bats in a land-bridge island system. Biol Conserv 143:597-608*

Evelyn MJ, Stiles DA (2003) Roosting requirements of two frugivorous bats (Sturnira lilium and Artibeus intermedius) in fragmented neotropical forest. Biotropica 35:405-418*

Ewers RM, Didham RK (2006a) Confounding factors in the detection of species responses to habitat fragmentation. Biol Rev 81:117-142

Ewers RM, Didham RK (2006b) Continuous response functions for quantifying the strength of edge effects. J Appl Ecol 43:527-536

Ewers RM, Didham RK (2007) Habitat fragmentation: panchreston or paradigm? Trends Ecol Evol 22:511

Ewers RM, Boyle MJ, Gleave RA et al (2015) Logging cuts the functional importance of invertebrates in tropical rainforest. Nat Commun 6:6836

Fahrig L (2003) Effects of habitat fragmentation on biodiversity. Annu Rev Ecol Evol Syst 34:487-515

Faria D (2006) Phyllostomid bats of a fragmented landscape in the north-eastern Atlantic forest, Brazil. J Trop Ecol 22:531-542*

Faria D, Baumgarten J (2007) Shade cacao plantations (Theobroma cacao) and bat conservation in southern Bahia, Brazil. Biodivers Conserv 16:291-312*

Faria D, Laps RR, Baumgarten J et al (2006) Bat and bird assemblages from forests and shade cacao plantations in two contrasting landscapes in the Atlantic Forest of southern Bahia, Brazil. Biodivers Conserv 15:587-612* 
Faria D, Paciencia MLB, Dixo M et al (2007) Ferns, frogs, lizards, birds and bats in forest fragments and shade cacao plantations in two contrasting landscapes in the Atlantic forest, Brazil. Biodivers Conserv 16:2335-2357*

Farneda FZ, Rocha R, López-Baucells A, Groenenberg M, Silva I, Palmeirim JM, Bobrowiec PED \& Meyer CFJ (2015) Trait-related responses to habitat fragmentation in Amazonian bats. J Appl Ecol 52:1381-1391*

Fenton MB, Acharya L, Audet D et al (1992) Phyllostomid bats (Chiroptera: Phyllostomidae) as indicators of habitat disruption in the Neotropics. Biotropica 24:440-446*

Fischer J, Lindenmayer DB (2007) Landscape modification and habitat fragmentation: a synthesis. Glob Ecol Biogeogr 16:265-280

Fletcher RJ Jr, Ries L, Battin J et al (2007) The role of habitat area and edge in fragmented landscapes: definitively distinct or inevitably intertwined? Can J Zool 85:1017-1030

Fukuda D, Tisen OB, Momose K et al (2009) Bat diversity in the vegetation mosaic around a lowland dipterocarp forest of Borneo. Raffles Bull Zool 57:213-221*

Furey N, Mackie I, Racey P (2010) Bat diversity in Vietnamese limestone karst areas and the implications of forest degradation. Biodivers Conserv 19:1821-1838*

Galindo-González J, Sosa VJ (2003) Frugivorous bats in isolated trees and riparian vegetation associated with human-made pastures in a fragmented tropical landscape. Southwest Nat 48:579-589*

Galindo-González J, Guevara S, Sosa VJ (2000) Bat- and bird-generated seed rains at isolated trees in pastures in a tropical rainforest. Conserv Biol 14:1693-1703*

García QS, Rezende JLP, Aguiar LMS (2000) Seed dispersal by bats in a disturbed area of Southeastern Brazil. Rev Biol Trop 48:125-128*

García-Estrada C, Damon A, Sánchez-Hernández C et al (2012) Diets of frugivorous bats in montane rain forest and coffee plantations in southeastern Chiapas, Mexico. Biotropica 44:394-401*

García-Morales R, Chapa-Vargas L, Galindo-González J et al (2012) Seed dispersal among three different vegetation communities in the Huasteca region, Mexico, analyzed from bat feces. Acta Chiropt 14:357-367*

Gardner TA, Barlow J, Chazdon R et al (2009) Prospects for tropical forest biodiversity in a human-modified world. Ecol Lett 12:561-582

Gardner TA, Barlow J, Sodhi NS et al (2010) A multi-region assessment of tropical forest biodiversity in a human-modified world. Biol Conserv 143:2293-2300

Gibbs HK, Ruesch AS, Achard F et al (2010) Tropical forests were the primary sources of new agricultural land in the 1980s and 1990s. Proc Natl Acad Sci 107:16732-16737

Gibson L, Lee TM, Koh LP et al (2011) Primary forests are irreplaceable for sustaining tropical biodiversity. Nature 478:378-381

Gorchov DL, Rondon XJ, Cornejo F et al (2013) Edge effects in recruitment of trees, and relationship to seed dispersal patterns, in cleared strips in the Peruvian Amazon. Ecol Res 28:53-65*

Gorresen PM, Willig MR (2004) Landscape responses of bats to habitat fragmentation in Atlantic forest of Paraguay. J Mammal 85:688-697*

Gorresen PM, Willig MR, Strauss RE (2005) Multivariate analysis of scale-dependent associations between bats and landscape structure. Ecol Appl 15:2126-2136*

Griscom HP, Kalko EKV, Ashton MS (2007) Frugivory by small vertebrates within a deforested, dry tropical region of Central America. Biotropica 39:278-282*

Guevara S, Laborde J, Sanchez-Rios G (2004) Rain forest regeneration beneath the canopy of fig trees isolated in pastures of Los Tuxtlas, Mexico. Biotropica 36:99-108*

Hamann A, Curio E (1999) Interactions among frugivores and fleshy fruit trees in a Philippine submontane rainforest. Conserv Biol 13:766-773*

Hansen MC, Potapov PV, Moore R et al (2013) High-resolution global maps of 21st-century forest cover change. Science 342:850-853

Hanson T, Brunsfeld S, Finegan B et al (2007) Conventional and genetic measures of seed dispersal for Dipteryx panamensis (Fabaceae) in continuous and fragmented Costa Rican rain forest. J Trop Ecol 23:635-642* 
Harper KA, MacDonald SE, Burton PE et al (2005) Edge influence on forest structure and composition in fragmented landscapes. Conserv Biol 19:768-782

Harrison ME, Boonman A, Cheyne SM et al (2012) Biodiversity monitoring protocols for REDD+: can a one-size-fits-all approach really work? Trop Conserv Sci 5:1-11

Harvey CA, Medina A, Sanchez DM et al (2006) Patterns of animal diversity in different forms of tree cover in agricultural landscapes. Ecol Appl 16:1986-1999*

Hayman DT, Bowen RA, Cryan PM et al (2013) Ecology of zoonotic infectious diseases in bats: current knowledge and future directions. Zoonoses Public Health 60:2-21

Henry M, Cosson JF, Pons JM (2007a) Abundance may be a misleading indicator of fragmentation-sensitivity: The case of fig-eating bats. Biol Conserv 139:462-467*

Henry M, Pons J-M, Cosson J-F (2007b) Foraging behavior of a frugivorous bat helps bridge landscape connectivity and ecological processes in a fragmented rainforest. J Anim Ecol 76:801-813*

Henry M, Cosson JF, Pons JM (2010) Modelling multi-scale spatial variation in species richness from abundance data in a complex neotropical bat assemblage. Ecol Modell 221:2018-2027*

Ingle NR (2003) Seed dispersal by wind, birds, and bats between Philippine montane rainforest and successional vegetation. Oecologia 134:251-261*

Jetz W, Wilcove DS, Dobson AP (2007) Projected impacts of climate and land-use change on the global diversity of birds. PLoS Biol 5:e157

Jones G, Jacobs DS, Kunz TH et al (2009) Carpe noctem: the importance of bats as bioindicators. Endanger Spec Res 8:93-115

Kalka MB, Smith AR, Kalko EKV (2008) Bats limit arthropods and herbivory in a tropical forest. Science 320:71

Kingston T (2013) Response of bat diversity to forest disturbance in Southeast Asia: insights from long-term research in Malaysia. In: Adams RA, Pedersen SC (eds) Bat evolution, ecology, and conservation. Springer New York, pp 169-185

Klingbeil BT, Willig MR (2009) Guild-specific responses of bats to landscape composition and configuration in fragmented Amazonian rainforest. J Appl Ecol 46:203-213*

Klingbeil BT, Willig MR (2010) Seasonal differences in population-, ensemble- and communitylevel responses of bats to landscape structure in Amazonia. Oikos 119:1654-1664*

Kunz TH, de Torrez EB, Bauer D et al (2011) Ecosystem services provided by bats. Ann NY Acad Sci 1223:1-38

Kupfer JA, Malanson GP, Franklin SB (2006) Not seeing the ocean for the islands: the mediating influence of matrix-based processes on forest-fragmentation effects. Glob Ecol Biogeogr 15:8-20

Laurance WF (2008) Theory meets reality: how habitat fragmentation research has transcended island biogeographic theory. Biol Conserv 141:1731-1744

Laurance WF, Camargo JLC, Luizão RCC et al (2011) The fate of Amazonian forest fragments: A 32-year investigation. Biol Conserv 144:56-67

Laurance WF, Sayer J, Cassman KG (2014) Agricultural expansion and its impacts on tropical nature. Trends Ecol Evol 29:107-116

Law BS, Lean M (1999) Common blossom bats (Syconycteris australis) as pollinators in fragmented Australian tropical rainforest. Biol Conserv 91:201-212*

Lee TM, Jetz W (2008) Future battlegrounds for conservation under global change. Proc R Soc B 275:1261-1270

Lindenmayer DB, Fischer J (2006) Habitat fragmentation and landscape change. Island Press, Washington, D.C.

Lindenmayer DB, Laurance WF (2012) A history of hubris-cautionary lessons in ecologically sustainable forest management. Biol Conserv 151:11-16

Lindenmayer DB, Wood J, McBurney L et al (2011) Cross-sectional vs. longitudinal research: a case study of trees with hollows and marsupials in Australian forests. Ecol Monogr 81:557-580

Louzada J, Gardner T, Peres C et al (2010) A multi-taxa assessment of nestedness patterns across a multiple-use Amazonian forest landscape. Biol Conserv 143:1102-1109*

Luskin MS (2010) Flying foxes prefer to forage in farmland in a tropical dry forest landscape mosaic in Fiji. Biotropica 42:246-250* 
Maas B, Clough Y, Tscharntke T (2013) Bats and birds increase crop yield in tropical agroforestry landscapes. Ecol Lett 16:1480-1487*

MacArthur RH, Wilson EO (1967) The theory of island biogeography. Princeton University Press, Princeton

Mancina CA, García-Rivera L, Capote RT (2007) Habitat use by phyllostomid bat assemblages in secondary forests of the 'Sierra del Rosario' biosphere reserve, Cuba. Acta Chiropt 9:203-218*

McCulloch ES, Sebastián Tello J, Whitehead A et al (2013) Fragmentation of Atlantic Forest has not affected gene flow of a widespread seed-dispersing bat. Mol Ecol 22:4619-4633*

Medellín RA, Gaona O (1999) Seed dispersal by bats and birds in forest and disturbed habitats of Chiapas, Mexico. Biotropica 31:478-485*

Medellín RA, Equihua M, Amin MA (2000) Bat diversity and abundance as indicators of disturbance in Neotropical rainforests. Conserv Biol 14:1666-1675*

Medina A, Harvey CA, Sánchez Merlo D et al (2007) Bat diversity and movement in an agricultural landscape in Matiguás, Nicaragua. Biotropica 39:120-128*

Melo FPL, Rodriguez-Herrera B, Chazdon RL et al (2009) Small tent-roosting bats promote dispersal of large-seeded plants in a Neotropical forest. Biotropica 41:737-743*

Melo FPL, Arroyo-Rodríguez V, Fahrig L et al (2013) On the hope for biodiversity-friendly tropical landscapes. Trends Ecol Evol 28:462-468

Mendenhall CD, Karp DS, Meyer CFJ et al (2014) Predicting biodiversity change and averting collapse in agricultural landscapes. Nature 509:213-217*

Mendes P, Vieira TB, Oprea M et al (2009) Long-distance movement of Artibeus lituratus (Chiroptera: Phyllostomidae) in the state of Espirito Santo, Brazil. Ecotropica 15:43-46*

Meyer CFJ, Kalko EKV (2008a) Assemblage-level responses of phyllostomid bats to tropical forest fragmentation: land-bridge islands as a model system. J Biogeogr 35:1711-1726*

Meyer CFJ, Kalko EKV (2008b) Bat assemblages on Neotropical landbridge islands: nested subsets and null model analyses of species co-occurrence patterns. Divers Distrib 14:644-654*

Meyer CFJ, Fründ J, Pineda Lizano W et al (2008) Ecological correlates of vulnerability to fragmentation in Neotropical bats. J Appl Ecol 45:381-391*

Meyer CFJ, Kalko EKV, Kerth G (2009) Small-scale fragmentation effects on local genetic diversity in two phyllostomid bats with different dispersal abilities in Panama. Biotropica 41:95-102*

Monadjem A, Ellstrom M, Maldonaldo C et al (2010) The activity of an insectivorous bat Neoromicia nana on tracks in logged and unlogged forest in tropical Africa. Afr J Ecol 48:1083-1091*

Moreno CE, Halffter G (2001) Spatial and temporal analysis of alpha, beta and gamma diversities of bats in a fragmented landscape. Biodivers Conserv 10:367-382*

Muscarella R, Fleming TH (2007) The role of frugivorous bats in tropical forest succession. Biol Rev 82:573-590

Numa C, Verdú JR, Sánchez-Palomino P (2005) Phyllostomid bat diversity in a variegated coffee landscape. Biol Conserv 122:151-158*

Ochoa GJ (2000) Effects of selective logging on the diversity of small mammals in the lowland forests of the Venezuelan Guyana region. Biotropica 32:146-164*

Ostfeld RS, Keesing F (2012) Effects of host diversity on infectious disease. Annu Rev Ecol Evol Syst 43:157-182

Pardini R, Faria D, Accacio GM et al (2009) The challenge of maintaining Atlantic forest biodiversity: a multi-taxa conservation assessment of specialist and generalist species in an agroforestry mosaic in southern Bahia. Biol Conserv 142:1178-1190*

Pech-Canche JM, Moreno CE, Halffter G (2011) Additive partitioning of phyllostomid bat richness at fine and coarse spatial and temporal scales in Yucatan, Mexico. Ecoscience 18:42-51

Peel AJ, Sargan DR, Baker KS et al (2013) Continent-wide panmixia of an African fruit bat facilitates transmission of potentially zoonotic viruses. Nat Commun 4:2770

Pereira HM, Leadley PW, Proença V et al (2010) Scenarios for global biodiversity in the 21 st century. Science 330:1496-1501 
Perfecto I, Vandermeer J (2008) Biodiversity conservation in tropical agroecosystems. Ann NY Acad Sci 1134:173-200

Peters SL, Malcolm JR, Zimmerman BL (2006) Effects of selective logging on bat communities in the Southeastern Amazon. Conserv Biol 20:1410-1421*

Phalan B, Bertzky M, Butchart SHM et al (2013) Crop expansion and conservation priorities in tropical countries. PLoS ONE 8:e51759

Phommexay P, Satasook C, Bates P et al (2011) The impact of rubber plantations on the diversity and activity of understorey insectivorous bats in southern Thailand. Biodivers Conserv 20:1441-1456*

Pilosof S, Dick CW, Korine C et al (2012) Effects of anthropogenic disturbance and climate on patterns of bat fly parasitism. PLoS ONE 7:e41487*

Pina SMS, Meyer CFJ, Zortéa M (2013) A comparison of habitat use by phyllostomid bats (Chiroptera: Phyllostomidae) in natural forest fragments and Eucalyptus plantations in the Brazilian Cerrado. Chiroptera Neotrop 19:14-30*

Pineda E, Moreno C, Escobar F et al (2005) Frog, bat, and dung beetle diversity in the cloud forest and coffee agroecosystems of Veracruz, Mexico. Conserv Biol 19:400-410*

Pinto N, Keitt TH (2008) Scale-dependent responses to forest cover displayed by frugivore bats. Oikos 117:1725-1731*

Pons J-M, Cosson J-F (2002) Use of forest fragments by animalivorous bats in French Guiana. Rev Ecol-Terre Vie 57:117-130*

Prasetyo PN, Noerfahmy S, dan Tata HL (2011) Jenis-jenis Kelelawar Agroforest Sumatera (Bat species in Sumatran agroforest). World Agroforestry Centre-ICRAF, SEA Regional Office, Bogor, Indonesia*

Presley SJ, Willig MR, Wunderle Jr. JM et al (2008) Effects of reduced-impact logging and forest physiognomy on bat populations of lowland Amazonian forest. J Appl Ecol 45:14-25*

Presley SJ, Willig MR, Castro-Arellano I et al (2009a) Effects of habitat conversion on temporal activity patterns of phyllostomid bats in lowland Amazonian rain forest. J Mammal 90:210-221*

Presley SJ, Willig MR, Saldanha LN et al (2009b) Reduced-impact logging has little effect on temporal activity of frugivorous bats (Chiroptera) in lowland Amazonia. Biotropica 41:369-378*

Pullin AS, Stewart GB (2006) Guidelines for systematic review in conservation and environmental management. Conserv Biol 20:1647-1656

Putz FE, Sist P, Fredericksen T et al (2008) Reduced-impact logging: Challenges and opportunities. For Ecol Manage 256:1427-1433

Putz FE, Zuidema PA, Synnott T et al (2012) Sustaining conservation values in selectively logged tropical forests: the attained and the attainable. Conserv Lett 5:296-303

Quesada M, Stoner KE, Rosas-Guerrero V et al (2003) Effects of habitat disruption on the activity of nectarivorous bats (Chiroptera: Phyllostomidae) in a dry tropical forest: implications for the reproductive success of the neotropical tree Ceiba grandiflora. Oecologia 135:400-406*

Quesada M, Stoner KE, Lobo JA et al (2004) Effects of forest fragmentation on pollinator activity and consequences for plant reproductive success and mating patterns in bat-pollinated bombacaceous trees. Biotropica 36:131-138*

Quesada M, Herrerias-Diego Y, Lobo JA et al (2013) Long-term effects of habitat fragmentation on mating patterns and gene flow of a tropical dry forest tree, Ceiba aesculifolia (Malvaceae: Bombacoideae). Am J Bot 100:1095-1101*

Ramage BS, Sheil D, Salim HMW et al (2013) Pseudoreplication in tropical forests and the resulting effects on biodiversity conservation. Conserv Biol 27:364-372

Ribeiro MC, Metzger JP, Martensen AC et al (2009) The Brazilian Atlantic Forest: how much is left, and how is the remaining forest distributed? Implications for conservation. Biol Conserv 142:1141-1153

Ries L, Sisk TD (2010) What is an edge species? The implications of sensitivity to habitat edges. Oikos 119:1636-1642 
Ripperger SP, Tschapka M, Kalko EKV et al (2013) Life in a mosaic landscape: anthropogenic habitat fragmentation affects genetic population structure in a frugivorous bat species. Conserv Genet 14:925-934*

Rossiter SJ, Zubaid A, Mohd-Adnan A et al (2012) Social organization and genetic structure: insights from codistributed bat populations. Mol Ecol 21:647-661*

Sala OE, Chapin FS, Armesto JJ et al (2000) Global biodiversity scenarios for the year 2100 . Science 287:1770-1774

Salas-Rojas M, Sánchez-Hernández C, Romero-Almaraz MdL et al (2004) Prevalence of rabies and LPM paramyxovirus antibody in non-hematophagous bats captured in the Central Pacific coast of Mexico. Trans R Soc Trop Med Hyg 98:577-584*

Saldaña-Vázquez R, Sosa V, Hernández-Montero J et al (2010) Abundance responses of frugivorous bats (Stenodermatinae) to coffee cultivation and selective logging practices in mountainous central Veracruz, Mexico. Biodivers Conserv 19:2111-2124*

Saldaña-Vázquez RA, Munguía-Rosas MA (2013) Lunar phobia in bats and its ecological correlates: a meta-analysis. Mamm Biol 78:216-219

Sampaio EM, Kalko EKV, Bernard E et al (2003) A biodiversity assessment of bats (Chiroptera) in a tropical lowland rainforest of Central Amazonia, including methodological and conservation considerations. Stud Neotrop Fauna Environ 38:17-31*

Schulze MD, Seavy NE, Whitacre DF (2000) A comparison of the phyllostomid bat assemblages in undisturbed neotropial forest and in forest fragments of a slash-and-burn farming mosaic in Petén, Guatemala. Biotropica 32:174-184*

Sedlock JL, Weyandt SE, Cororan L et al (2008) Bat diversity in tropical forest and agro-pastoral habitats within a protected area in the Philippines. Acta Chiropt 10:349-358*

Smith EP (2013) BACI design. Encyclopedia of environmetrics. Wiley, London

Stoner KE, Quesada M, Rosas-Guerrero V et al (2002) Effects of forest fragmentation on the Colima long-nosed bat (Musonycteris harrisoni) foraging in tropical dry forest of Jalisco, Mexico. Biotropica 34:462-467*

Storfer A, Murphy MA, Spear SF et al (2010) Landscape genetics: where are we now? Mol Ecol 19:3496-3514

Struebig MJ, Kingston T, Zubaid A et al (2008) Conservation value of forest fragments to Palaeotropical bats. Biol Conserv 141:2112-2126*

Struebig MJ, Kingston T, Zubaid A et al (2009) Conservation importance of limestone karst outcrops for Palaeotropical bats in a fragmented landscape. Biol Conserv 142:2089-2096*

Struebig MJ, Kingston T, Petit EJ et al (2011) Parallel declines in species and genetic diversity in tropical forest fragments. Ecol Lett 14:582-590*

Struebig MJ, Turner A, Giles E et al (2013) Quantifying the biodiversity value of repeatedly logged rainforests: gradient and comparative approaches from Borneo. In: Guy W, Eoin JOG (eds) Advances in ecological research, vol 48. Academic Press, New York, pp 183-224*

Struebig M, Wilting A, Gaveau DLA et al (2015) Targeted conservation safeguards a biodiversity hotspot from climate and land-cover change. Curr Biol 25:372-378

Syamsi F (2013) Chiroptera community in oil palm plantation. J Indonesian Nat Hist 1:49*

Tilman D, Balzer C, Hill J et al (2011) Global food demand and the sustainable intensification of agriculture. Proc Natl Acad Sci 108:20260-20264

Trevelin LC, Silveira Mc, Port-Carvalho M et al (2013) Use of space by frugivorous bats (Chiroptera: Phyllostomidae) in a restored Atlantic forest fragment in Brazil. Ecol Manage 291:136-143*

Tscharntke T, Clough Y, Bhagwat SA et al (2011) Multifunctional shade-tree management in tropical agroforestry landscapes-a review. J Appl Ecol 48:619-629

Villard M-A, Metzger JP (2014) Beyond the fragmentation debate: a conceptual model to predict when habitat configuration really matters. J Appl Ecol 51:309-318

Vleut I, Levy-Tacher SI, Galindo-González J et al (2012) Tropical rain-forest matrix quality affects bat assemblage structure in secondary forest patches. J Mammal 93:1469-1479* 
Vleut I, Levy-Tacher SI, de Boer WF et al (2013) Tropical secondary forest management influences frugivorous bat composition, abundance and fruit consumption in Chiapas, Mexico. PLoS ONE 8:e77584*

Voigt CC, Voigt-Heucke SL, Kretzschmar AS (2012) Isotopic evidence for seed transfer from successional areas into forests by short-tailed fruit bats (Carollia spp.; Phyllostomidae). J Trop Ecol 28:181-186*

Wanger TC, Darras K, Bumrungsri S et al (2014) Bat pest control contributes to food security in Thailand. Biol Conserv 171:220-223

Wieland LM, Mesquita RCG, Bobrowiec PED et al (2011) Seed rain and advance regeneration in secondary succession in the Brazilian Amazon. Trop Conserv Sci 4:300-316*

Williams-Guillén K, Perfecto I (2010) Effects of agricultural intensification on the assemblage of leaf-nosed bats (Phyllostomidae) in a coffee landscape in Chiapas, Mexico. Biotropica 42:605-613*

Williams-Guillén K, Perfecto I (2011) Ensemble composition and activity levels of insectivorous bats in response to management intensification in coffee agroforestry systems. PLoS ONE 6:e16502*

Williams-Guillén K, Perfecto I, Vandermeer J (2008) Bats limit insects in a Neotropical agroforestry system. Science 320:70*

Willig MR (2001) Exploring biodiversity in time and space: Profitable directions for mammalogy in the 21st century. Mastozool Neotrop 8:107-109

Wright SJ, Muller-Landau H (2006) The future of tropical forest species. Biotropica 38:287-301

Willig MR, Patterson BD, Stevens RD (2003) Patterns of range size, richness, and body size in the Chiroptera. In: Kunz TH, Fenton MB (eds) Bat Ecology. University of Chicago Press, Chicago, pp 580-621

Willig MR, Presley SJ, Bloch CP et al. (2007) Phyllostomid bats of lowland Amazonia: Effects of habitat alteration on abundance. Biotropica 39:737-746*

Zubaid A (1993) A comparison of the bat fauna between a primary and fragmented secondary forest in peninsular Malaysia. Mammalia 57:201-206* 